\title{
Role of the KNOTTED1-LIKE HOMEOBOX Protein (KD1) in regulating tomato flower pedicel abscission at early and late stages of the process
}

\section{Srivignesh Sundaresan}

Agricultural Research Organization Volcani Center

\section{Sonia Philosoph-Hadas}

Agricultural Research Organization Volcani Center

\section{Chao Ma}

University of California Davis Department of Plant Sciences

\section{Cai-Zhong Jiang}

University of California Davis Department of Plant Sciences

Joseph Riov

Hebrew University of Jerusalem Robert H Smith Faculty of Agriculture Food and Environment

\section{Betina Kochanek}

Agricultural Research Organization Volcani Center

\section{Shoshana Salim}

Agricultural Research Organization Volcani Center

\section{Michael S. Reid}

University of California Davis Department of Plant Sciences

Shimon Meir ( $\nabla$ shimonm@volcani.agri.gov.il)

https://orcid.org/0000-0002-5792-6862

\section{Research article}

Keywords: Auxin, epigenetic, ethylene, exocytosis, flower abscission zone, gibberellin, transcription factors

Posted Date: October 10th, 2019

DOl: https://doi.org/10.21203/rs.2.15854/v1

License: (c) (1) This work is licensed under a Creative Commons Attribution 4.0 International License. Read Full License

Version of Record: A version of this preprint was published at Physiologia Plantarum on September 20th, 2021. See the published version at https://doi.org/10.1111/ppl.13560. 


\section{Abstract}

Background The KNOTTED1-LIKE HOMEOBOX PROTEIN1 ( KD1) gene is highly expressed in flower and leaf abscission zones (AZs). RNA-antisense silencing of KD1 was shown to delay tomato pedicel and petiole abscission, induced by flower or leaf removal, respectively. KD1 was found to regulate flower pedicel abscission via alteration of auxin gradient through the flower AZ (FAZ), and disruption of the auxin response at the early stages of the abscission process. The present work was aimed to further understand how KD1 regulates signaling factors and regulatory genes involved in the delay of pedicel abscission using the silenced KD1 lines. For this purpose we performed a large scale transcriptome profiling of the FAZ at various time points after flower removal, using a customized AZ-specific microarray.

Results The results highlighted a differential expression of regulatory genes in the FAZ of KD1 -silenced plants compared to the wild type (WT). These genes were controlled by KD1 before and after abscission induction. In the KD1 -silenced plants, KD1 expression already decreased at zero time before flower removal, resulting in altered expression of regulatory genes, including epigenetic modifiers, transcription factors (TFs), post-translation regulators, and antioxidative defense components. The increased expression of these regulatory genes, and genes related to exocytosis and gibberellin perception, observed in the WT FAZ, was inhibited in the KD1- silenced plants at $4 \mathrm{~h}$ after flower removal. This response led to an inhibited abscission phenotype and downregulation of genes involved in abscission execution and defense in the KD1 -silenced plants.

Conclusions The data suggest that KD1 is a master regulator in tomato flower abscission. Some of the altered genes might directly affect auxin homeostasis and transport, resulting in slowing down auxin depletion in the FAZ. This probably delayed the subsequent cascade of the molecular events described above. The data obtained suggest that the inhibitory effect of KD1 silencing on flower pedicel abscission is not limited to manipulation of auxin levels and response as previously reported, but it probably also operates via alteration of other regulatory pathways that delay the acquisition of the competence of the FAZ cells to respond to ethylene signaling.

\section{Background}

It is well documented that removal of the leaf blades or flowers, the major sources of auxin production, or application of polar auxin transport inhibitors induce petiole or pedicel abscission, respectively, as a result of reduction in auxin transport to the organ abscission zone (AZ). This leads to altered expression of auxin-related genes and upregulation of ethylene-related genes [1] as well as to differential expression of other regulatory genes in the flower AZ (FAZ) of tomato (Solanum lycopersicum).. These events resulted in the acquisition of the FAZ cell competence to respond to ethylene signaling [1-5].

In a previous study, focused on the tomato pedicel abscission process induced by flower removal, we identified by transcriptome microarray analysis, several genes, the expression of which was modified in 
the FAZ but remained unchanged in the pedicel non-AZ (NAZ) [2]. These genes were suggested to be involved in the acquisition of the FAZ cell competence to respond to ethylene signaling following auxin depletion [2]. Out of these FAZ-specifically expressed genes, two genes were further studied for their functional roles in abscission. These included the KD1 gene, which encodes the KNOTTED1-LIKE HOMEOBOX PROTEIN1 that belongs to class I KNOX family [6], and the THyPRP gene, which encodes theTomato Hybrid Proline-Rich Protein [7]. We previously showed that downregulation of KD1 by antisense significantly delayed pedicel and petiole abscission in tomato plants by affecting auxin levels in the $A Z$ and auxin gradient from the distal to the proximal region of the FAZ without impairing their growth and development [6]. Additionally, we recently reported that downregulation of THyPRP by silencing delayed pedicel abscission by regulating the FAZ cell competence to respond to ethylene signals [7]. The present study focused on further elucidation of the role of KD1 in abscission, and understanding its mode of action, using new tools that were not available in our previous work.

Three knotted proteins, KNAT1, KNAR2 and KNAT6 in Arabidopsis, as well as the knotted TKN4 in tomato, were previously demonstrated to be involved in flower organ abscission, acting as downstream factors of the INFLORESCENCE DEFICIENT IN ABSCISSION (IDA)-HAESA pathway [8-10]. Recently, a KNOX protein, $\mathrm{OSH} 15$, was demonstrated to enhance seed shattering in rice by directly inhibiting lignin biosynthesis genes [11]. Apart of being involved in abscission processes, KD1 and KNOX genes have a welldocumented role in leaf development, and are known to modulate boundary separation and proximaldistal axis development in leaves of dicots [12-14]. In monocots, the KNOX regulatory network was reported to play a role in shoot apical meristem maintenance in rice and maize $[15,16]$. In different plant systems, the class I KNOX family proteins were found to regulate several genes involved in biosynthesis and signal transduction of various plant hormones, various TFs and lignin synthesis [17]. Recently, a KNOXI transcription factor (TF) was demonstrated to regulate floral fate in Arabidopsis, further clarifying the role of KNOX TFs in the specification of flower meristem identity [18].

Manipulating KD1 expression affected various aspects of plant development, which were all related to the KD1 role in auxin gradient responses [19], and the KNOX protein Knotted1 was reported to directly control the auxin signaling pathway in maize at all levels, including auxin synthesis, transport, and signaling [20]. Indeed, our previous work, which investigated the role of KD1 in abscission, demonstrated a strong effect of KD1 on the auxin gradient in the FAZ [6]. Thus, the $K D 1$ gene was silenced, under the control of the AZspecific promoter, Tomato Abscission Polygalacturonase4 (TAPG4) $[2,6,21,22]$, to study the changes in gene expression profiles in the tomato FAZ shortly (4 h) after flower removal, in the TAPG4::antisense KD1 plants compared to the wild type (WT). The data obtained showed that the involvement of $K D 1$ in abscission regulation was associated with auxin transporters and signaling components, and that the changes in $K D 1$ expression modulated the auxin concentration and response gradient in the FAZ. Reducing KD1 transcript abundance, which is highly expressed in the AZs, delayed organ abscission, but it did not prevent the process, suggesting that KD1 is part of a complex system controlling the abscission process [6]. 
Our previous study [6] raised some questions that remained unsolved. These included: a) how $K D 1$ is regulating the auxin-related genes; $b$ ) what is the role of KD1 in regulation of other signaling factors and regulatory genes involved in the delay of pedicel abscission at zero time and at the early $(4 \mathrm{~h})$ and late $(8-20 \mathrm{~h})$ stages of the abscission process occurring after flower removal. To answer these questions, we performed in the present study a detailed transcriptome analysis of the FAZ and the NAZ of WT plants compared to the FAZ of the TAPG4::antisense KD1 plants, at various time points after flower removal, using a newly developed customized AZ-specific microarray [22]. The use of this customized AZ-specific microarray in a time course analysis, allowed to expand the database of changes in gene expression occurring at the early stage of pedicel abscission, since it contains more gene probes than those that were previously used by Ma et al. [6]. The results obtained in the present study highlighted expression of regulatory genes in the FAZ, which seem to be controlled by KD1 before and after abscission induction. These genes might have a role in regulating the acquisition of the FAZ cell competence to respond to ethylene signaling, or in controlling abscission in a different mode of action.

\section{Results And Discussion}

\section{Downregulation of $K D 1$ in the AZ inhibits tomato pedicel and petiole abscission}

Quantitative reverse transcription (qRT-PCR) demonstrated that the $K D 1$ transcript was predominately expressed in the FAZ, and its expression was downregulated to very low levels within $8 \mathrm{~h}$ after flower removal (Fig. 1). This rapid decrease in KD1 expression in the tomato FAZ after flower removal was already demonstrated in our previous publications $[2,6]$. Pretreatment with the ethylene inhibitor 1methycylopropene (1-MCP) did not affect the expression of $K D 1$, but application of IAA after flower removal prevented the decrease in its expression [2]. These data indicate that $K D 1$ expression in the FAZ is IAA-dependent, and that the decrease in its expression is a result of IAA depletion after flower removal. Similar results were reported for other Knotted family members, such as Knotted TKN2/LET6 (AF000141) and knotted TKN4 (AF533597) [2]. The involvement of three knotted proteins, KNAT1, KNAT2, and KNAT6, was also reported for the INFLORESCENCE DEFICIENT IN ABSCISSION (IDA)-HAE/HSL1-dependent flower organ abscission in Arabidopsis [8-10]. These observations suggest that KD1 and TKN4 could function as regulators of the acquisition of $A Z$ cell competence to respond to ethylene signaling after IAA depletion.

The important role of KD1 in tomato flower and leaf abscission, was previously demonstrated by virusinduced gene silencing (VIGS), andby antisense silencing under the AZ-specific promoter TAPG4, which led to delayed pedicel and petiole abscission [6]. The regulation of abscission by KD1 was found to be associated with modulation of the auxin concentration and response in the FAZ, leading to changes in the abundance of genes related to auxin transporters and signaling components [6]. We used the same lines $\mathrm{A}$ and $\mathrm{E}$ of generation $\mathrm{T} 4$ in the present study. 
The efficacy of $K D 1$ silencing is demonstrated by the qRT-PCR results (Fig. 2A). It is evident that the TAPG 4 promoter was very active in the FAZ [21], and $K D 1$ expression was downregulated by about $60 \%$ at zero time, and by about $70 \%$ at $4 \mathrm{~h}$ after flower removal, approximately at the same rates that were previously reported [6]. The microarray antisense probe showed increased expression of $K D 1$ between 4$20 \mathrm{~h}$ after flower removal (Fig. 2B). This antisense probe spanned the cloned fragment of KD1 (Fig. 2C). We expected a higher expression of the antisense probe also at zero time (Fig. 2B), because the expression of $K D 1$ in the transgenic plants decreased by $60 \%$ at this time point (Fig. 2A). At present we do not have a reasonable explanation for this unexpected results.

The antisense transgenic lines exhibited a very significant delay in pedicel and petiole abscission following abscission induction (Fig. 3). All the pedicels in the WT plants abscised at $20 \mathrm{~h}$ after flower removal, compared to only $40 \%$ of abscised pedicels in the TAPG4::antisense KD1 lines (Fig. 3A). Even at $48 \mathrm{~h}$ after flower removal, $25 \%$ of the pedicels in the transgenic plants still remained attached (data not shown). Petiole abscission of leaves at position 1 above the cotyledons reached $100 \%$ in the WT plants 4 days after leaf deblading and ethylene treatment, whereas in the TAPG4::antisense KD1 plants it reached only 60 and $70 \%$ abscission rate in the silenced lines A and E, respectively (Fig. 3B). The inhibition of petiole abscission in the transgenic plants was more significant in leaf position 4 (Fig. 3C), and also in leaf positions 2 and 3 (data not shown). The inhibition of petiole abscission after leaf deblading and ethylene treatment indicates that the petiole $A Z$ cells in the $K D 1$-silenced plants were less sensitive to ethylene treatment after auxin depletion. This supports our hypothesis that KD1 participates in regulating the AZ cell competence to respond to ethylene signals.

The molecular events in the process of tomato pedicel abscission were divided into two phases: early events ( 0 to $4 \mathrm{~h}$ after flower removal) and late events ( 8 to $14 \mathrm{~h}$ after flower removal) [2]. It is important to note that the previous transcriptomic experiment was performed with Solanum lycopersicum, cv. 'Shiran', in which $100 \%$ of pedicel abscission was obtained already at $14 \mathrm{~h}$ after flower removal, and therefore, the time point of $8 \mathrm{~h}$ was considered as a late stage. In the present study, we used Solanum lycopersicum, cv. 'New Yorker', in which $100 \%$ of pedicel abscission was obtained after $20 \mathrm{~h}$ (Fig. 3A), and therefore the time point of $8 \mathrm{~h}$ is considered as an early stage in the pedicel abscission execution process. The early events $(0-4 \mathrm{~h}$ ) probably lead to acquisition of the competence of FAZ cells to respond to ethylene signaling, and to increased endogenous ethylene biosynthesis. The late events include the execution of pedicel abscission and the development of the defense layer [2].

\section{B. Comparative transcriptome analysis in the FAZ of WT and of KD1-silenced plants using a customized AZ-specific array}

The microarray experiments were performed with two independently prepared samples, and probes showing at least 2-fold changes in signal intensity were selected for analysis, except for cell wall genes, for which lower intensities were considered. We observed that $64,76,96,111,304$, and 175 transcripts 
were upregulated and $120,126,319,58,397$, and 76 transcripts were downregulated in the FAZ samples of the $K D 1$-silenced vs WT plants, at $0,4,8,12,16$, and $20 \mathrm{~h}$ after flower removal, respectively (Table 1). The complete list of differentially expressed genes was generated and presented in Additional files 1-6: Tables S1-S6. Our microarray results reconfirmed the gene expression profiles reported by Ma et al. [6] in the FAZ at $4 \mathrm{~h}$ after flower removal, and revealed the potential role of other regulatory genes associated with $K D 1$ at the early stage of the pedicel abscission process (Figs. 4-8).

To validate the microarray assay results, we selected the following five genes, Cellulase1 (Cel1) (Solyc08g081620 / U13054); TAPG1 (Solyc02g067630 / U23053); TAPG4 (Solyc12g096750 / U70481); KD1 (Solyc06g072480 / AF375969); and THyPRP (Solyc07g043000 / X57076), and analyzed their expression by qRT-PCR. The qRT-PCR results were similar to the microarray results (Additional file 7: Figure S1).

\section{Mode of action of the inhibition of abscission in KD1- silenced plants}

The determination of the role of KD1 in the regulation of abscission in the tomato flower model system, based on the microarray results, should be related to changes in the expression of regulatory genes occurring specifically in the FAZ of the silenced plants at the early stages of pedicel abscission. Therefore, we focused mainly on genes, which showed a modified expression in the FAZ before flower removal (zero time) and at $4 \mathrm{~h}$ after flower removal. This early period represents the timing in which the FAZ cells acquire the competence to respond to ethylene signals, which initiates the abscission process $[1,2,7]$. The next abscission phase, the execution stage, which starts during the period of 4 to $8 \mathrm{~h}$ after flower removal, can also be regulated both by signals derived from the previous stage, as well as by signals generated during this stage, that cannot be distinguished from one another.

The results presented in Figures 5-9 are organized according to the pattern of gene expression rather than according to the function of the related proteins. Figures 5 and 6 present genes that were downregulated or upregulated, respectively, at zero time; Figures 7 and $8 \mathrm{~A}$ present genes that were upregulated or downregulated, respectively, at $4 \mathrm{~h}$ after flower removal and later on; and Figures $8 \mathrm{~B}$ and 9 present genes that were transiently upregulated or downregulated, respectively, mainly at $8 \mathrm{~h}$ after flower removal. Figures 10 and 11 present genes encoding cell wall degrading enzymes, as well as defense and boundary layer-related proteins, which function in the late abscission execution phases, $C$ and $D$, and not in the early regulatory events $[10,23]$.

\section{C1. Genes whose expression was specifically altered in the FAZ of $K D 1$-silenced plants at zero time}


As a result of the decrease in KD1 expression in the FAZ of the transgenic plants at zero time (Fig. 1), FAZspecific changes in the expression of some regulatory genes already occurred at this time (Figs. 4 and 5). Eight genes were downregulated in the transgenic plants at zero time, and their expression remained low up to the end of the experiment (Fig. 4), and 20 genes were upregulated and remained high or gradually decreased later on (Fig. 5). The downregulated genes included: two MADS-box genes (Fig. 4A1, A2); a High Mobility GroupHMG) TF (HMG-type nucleosome assembly factor) (Fig. 4B); an orthologue gene of the Arabidopsis Receptor-Like Kinase (RLK) (Fig. 4C); Enoyl-CoA Hydratase (Fig. 4D); NAD-specific Glutamate Dehydrogenase (GLDH) (Fig. 4E); and two Unknown Protein genes (Fig. 4F1, F2). All the downregulated genes in the FAZ of the silenced plants were not FAZ-specific, and were also significantly expressed in the WT NAZ (Fig. 4), except for RLK that was expressed at a low level in the WT NAZ (Fig. 4C).

Twenty genes were specifically upregulated in the FAZ of $K D 1$-silenced lines at zero time. These included: Four F-box family protein genes (Fig. 5A1-A3). The Regulatory Particle (RP) RPN3 (Fig. 5A5). Genomic DNA Chromosome 5P1 clone MBG8 (Fig. 5B1). Chromodomain Helicase DNA-binding protein4 (CHD4) (Fig. 5B2). Histone-lysine N-methyl transferase SETDB1 (Fig. 5B3). Three genes related to ethylene biosynthesis-two 1-Aminocyclopropane-1-Carboxylate Oxidase (ACO)-like proteins (Fig. 5C1, C2), and one ACO-homologue (Fig. 5C3); one AP2-like Ethylene Responsive Factor (ERF) (Fig. 5C4). Six Unknown Protein genes (Fig. 5D1-D6), a Serine-Threonine-Protein Phosphatase7 (Fig. 5E), and Glutaredoxin (Fig. $5 F)$. All these genes were significantly upregulated in the FAZ of the silenced lines from zero time up to at least $8 \mathrm{~h}$ after flower removal (Fig. 5).

Our results revealed that TAPG::antisense KD1 silencing altered the expression of the following major regulatory genes specifically in the FAZ at different levels of regulation: four genes related to plant epigenetics; two MADS-box homeobox TFs; eight post translation regulation genes related to ubiquitinbased protein degradation or phosphorylation/de-phosphorylation; and four ethylene-related genes. Some of these altered genes might trigger a cascade of molecular events, leading to alteration of the auxin levels and response in the FAZ at the early stages of the abscission process, resulting in a reduced competence of the FAZ cells to respond to ethylene, as demonstrated in a previous study [6]. Similarly, a reduced competence of the leaf $A Z$ to respond to ethylene after leaf deblading, was also obtained (Figs. $3 \mathrm{~B}, 3 \mathrm{C}$ ). The four ethylene-related genes, three $A C O$ genes (Fig. $5 \mathrm{C} 1-\mathrm{C} 3$ ) and one $E R F$ geneFig. $5 \mathrm{C} 4$ ), were unexpectedly upregulated in the FAZ of the silenced plants from zero time up to $20 \mathrm{~h}$. On the other hand, a transiently upregulation of one $A C O$ and two ERF genes in the WT FAZ was inhibited in the FAZ of the silenced plants (Fig. 6B1-B3). The expression pattern in the WT FAZ and NAZ at different time points of other ethylene-related genes involved in its biosynthesis (ACSs and ACOs) and perception (ETRs and CTRs) (data not shown), resembled the previously reported expression pattern for these genes [2]. The expression of these ethylene-related genes as well as the expression of other ERF genes, in the FAZ (21 out of 24 ERFs) after flower removal, was not affected by KD1 silencing (data not shown). These data suggest that the inhibition of pedicel abscission induced by $K D 1$ silencing may not necessarily be ethylene-mediated. 


\section{C2. Genes whose expression was specifically altered in the FAZ of $K D 1$-silenced plants at $4 \mathrm{~h}$ after flower removal}

The differentially regulated genes in the FAZ of the silenced plants at $4 \mathrm{~h}$ included various regulatory genes at different levels of regulation: epigenetics;TFs; post-translation such as kinase/phosphatase and protein degradation/ubiquitination; transporters; signal transduction; and oxidase/reductase gene families.

The expression of the TF gene encoding the Plant Homeodomain (PHD)-finger family protein, which was specifically upregulated in the WT FAZ at $4 \mathrm{~h}$ after flower removal and remained high up to $16 \mathrm{~h}$, was significantly inhibited in the FAZ of the silenced plants (Fig. 6C). The PHD finger protein has a metal binding RING domain (Cys3-His-Cys4) motif. The PHD domain has a conserved Zinc finger (Znf) domain in eukaryotic organisms. PHD finger in proteins related to epigenetics are involved in the interaction between proteins, especially the modification on histone of nucleosome, such as methylation, acetylation, and phosphorylation [24]. A similar expression pattern, i.e. upregulation in the WT FAZ and inhibition in the FAZ of the silenced plants, was also observed for two bHLH and Znf TF genes, SIbHLHO48 and SIbHLH046 (Fig. 6D1, D2). Some bHLH and Znf TF genes were previously reported to be involved in abscission of olive fruit and tomato flower pedicels $[2,25]$.

Six genes related to the $\mathrm{Ca}^{2+}$ signal transduction, two kinases and four $\mathrm{Ca}^{2+} /$ Calmodulin (CaM)-related, which were upregulated at $4 \mathrm{~h}$ after flower removal in the WT FAZ, were inhibited in the FAZ of the silenced plants (Fig. 6E1-E4, F1-F2). Calcium ions $\left(\mathrm{Ca}^{2+}\right)$ serve as a universal messenger involved in the modulation of diverse developmental and adaptive processes in response to various physiological stimuli $[26,27]$. Our results showed that the $\mathrm{Ca}^{2+} / \mathrm{CaM}$-mediated signal transduction plays a role in regulating the abscission process, and it is probably regulated by KD1. Previous reports on various abscission systems demonstrated the involvement and importance of $\mathrm{Ca}^{2+} / \mathrm{CaM}$ signaling in regulation of organ abscission. Thus, a cycle of water stress/rehydration, which induced citrus leaf abscission, resulted in upregulation of a CaM gene in the laminar leaf $A Z$ at $1 \mathrm{~h}$ after rehydration [28]. Induction of litchi fruitlet abscission by ethephon treatment resulted in expression changes of genes related to calcium transport and perception. Hence, 19 and 33 transcripts were up- and down-regulated, respectively, following the ethephon treatment, including CNGC genes [29]. Similarly, maturation of olive fruits, which induced their abscission, caused upregulation of CaM, CML, and Calcium-binding protein kinase genes in the fruit AZ [25]. Our results demonstrate that in the system of tomato pedicel abscission induced by flower removal KD1 silencing inhibited the upregulation of $\mathrm{Ca}^{2+} / \mathrm{CaM}$ signaling-related genes. These findings support the previous reports regarding the involvement of $\mathrm{Ca}^{2+} / \mathrm{CaM}$ signaling in organ abscission, and suggest that KD1 plays a significant role in regulating the $\mathrm{Ca}^{2+} / \mathrm{CaM}$ signal transduction.

Of particular interest is the exocytosis-related gene, Syntaxin, which encodes a membrane integrated protein, Q-Soluble N-Ethylmaleimide-sensitive Factor Attachment Protein Receptor (Q-SNARE), necessary for vesicle trafficking. This gene, which was upregulated in the WT FAZ, was significantly downregulated 
in the FAZ ofthe silenced plants (Fig. 6F3). The primary role of SNARE proteins is to mediate vesicle fusion with their target membrane bound compartments participating in exocytosis [30]. Previous reports showed that mobilization of the secretory pathway leads to the release of cell wall modifying enzymes to implement abscission [31, 32]. Additionally, Agusti et al. [28] reported the induction of several genes involved in vesicle trafficking, such as SNARE-like protein and Syntaxin, in citrus laminar AZ during leaf abscission induced by a cycle of water stress/rehydration. Analysis of gene expression in the melon fruit AZ revealed that a sequential induction of cell wall-degrading genes was associated with the upregulation of genes involved in endo- and exocytosis during mature fruit abscission [33].

Our analysis showed that the $A B C$ transportergene, an ATP-binding cassette transporter which belongs to the ABCA sub-family, was downregulated in the KD1-silenced plants compared to the WT (Fig. 6F4). This gene was shown to be involved in auxin transport, and is specifically expressed in the root system [34]. Similarly, the Coatomer beta subunit gene was also downregulated in the silenced plants (Fig. 6F1). The coat protein complex genes are responsible for reverse transport of recycled proteins from the Golgi and pre-Golgi compartments back to the ER and vice versa [35].

In the present work, two Cytochrome P450 genes were downregulated in the FAZ of the KD1-silenced plants up to $16 \mathrm{~h}$ after flower removal, reaching a similar level of expression to that observed in the WT FAZ at $20 \mathrm{~h}$ (Fig. 6G1, G2). Another Cytochrome P450 genewas also downregulated in the silenced plants up to $12 \mathrm{~h}$ after flower removal, and reached a similar level of expression as in the WT FAZ during 12-20 h (Fig. 8D). In Arabidopsis, the cytochrome P450s were shown to be involved in catalyzing the first step of tryptophan-dependent IAA biosynthesis [36]. The involvement of auxin and auxin-related gene expression in pedicel abscission of the WT and the KD1-silenced plants was reported previously [6].

Gene expression of several oxidase/reductase-related genes, such as Laccase (Fig. 6G3), Ascorbate Oxidase (AO) Fig. 6G5), Nitric Oxide (NO) reductase (Fig. 6G6), and Alcohol Dehydrogenase (Fig. 6H) was downregulated in the FAZ of the silenced plants, whereas in the WT FAZ these genes were upregulated during the abscission process. This suggests the involvement of oxidative processes in pedicel abscission.

\section{C3. Genes whose expression was specifically- and transiently-altered in the FAZ of KD1-silenced plants at $8 \mathrm{~h}$ after flower removal}

Several genes were specifically and transiently altered in the FAZ of $K D 1$-silenced plants at $8 \mathrm{~h}$ after flower removal, when the execution of cell separation had already started ( $22 \%$ of pedicel abscission was obtained in the WT-Fig. 3A). One set of genes represents diverse gene families that were transiently upregulated at $8 \mathrm{~h}$ in the silenced plants compared to the WT (Fig. 7E-L7). These genes included: $A$ ) CONSTANS interacting protein6 (Fig. 7E), which was shown to control flowering in response to photoperiod in Arabidopsis [37, 38], and leaf induction by cytokinins in tomato [39]. B) RNA-binding La 
domain protein (Fig. 7F), in which La acts as an RNA polymerase III (RNAP III) TF. C) cDNA clone (Fig. 7G), that also encodes an RNA-binding protein. D) Dopamine-Monooxygenase N-terminal (DOMON) domaincontaining protein, also called DoH (Fig. 7J), was originally identified in several secreted or cell surface proteins from plants and animals [40]. It is usually associated with other redox domains in larger proteins such as cytochromes b561, and has a suggested capability of transmembrane electron transport [4042].E) Seven Unknown Protein genes that have a similar expression pattern (Fig. 8L1-L7). Since these genes were upregulated in the FAZ of the silenced plants, in which pedicel abscission was significantly inhibited, unlike the WT in which pedicel abscission had already started (Fig. 3A), some of them might have an inhibitory role in the abscission process. Interestingly, seven stress defense-associated genes had the same expression pattern (Fig. 7K1-K7). However, it is not yet clear why these genes were upregulated in the silenced plants, which showed an inhibited abscission phenotype.

A second set of genes, which were specifically and transiently upregulated in the WT FAZ plants at $8 \mathrm{~h}$ after flower removal, when abscission had already started, were significantly inhibited in the silenced plants (Fig. 8). These data suggest that part of these genes encode proteins that regulate the abscission execution, including: A) Acid Phosphatase (Fig. 8A), whose activity was detected in the AZs of various species, such as sour and sweet cherry fruit, bean leaves, and hibiscus pedicels [43-45]. B) Inositol Hexakisphosphate Kinase3 (Fig. 8B1), to which the inositol hexakisphosphate kinase (InsP6) serves as a cofactor that recognizes auxin and the Aux/IAA polypeptide substrate, Transport Inhibitor Response1 (TIR1) [46]. C) Four $\mathrm{Ca}^{+2} / \mathrm{CaM}$-signal transduction regulatory genes, S/CNGC3 (Fig. 8B2), CaM-Like protein (Fig. 9B3), CaM-Binding protein - SICML35 (Fig. 8B4), and an AAA-ATPase family protein (Fig. 8K2). ATPases Associated with diverse cellular Activities (AAA ${ }^{+}$-ATPases) are AAA-type ATPase-family proteins, which are involved in cellular functions, such as vesicle transport, organelle assembly, membrane dynamics, and protein unfolding [47]. The Arabidopsis ATPase Family gene 1, (AFG1)-like protein 1 (AFG1L1), which belongs to the extended superfamily of $A A A^{+}-A T P a s e$ proteins, binds to CaM in a calcium-dependent manner through a CaM-binding site in its catalytic AAA-domain [48]. The function of these genes and the involvement of $\mathrm{Ca}^{+2} / \mathrm{CaM}$ in abscission were discussed in details above. Our data indicate that different $\mathrm{Ca}^{+2} / \mathrm{CaM}$ genes regulate early and late events in the abscission process. $D$ ) Different transporter-related genes, such as Glycosyltransferase (GTF) (Fig. 8C1), UDPGlycosyltransferase (Fig. 8C2), three $A B C / A B C$-2 type transporters (Fig. 8E1-E3), an Amino Acid Transporter (Fig. 9E4), and Vesicular Glutamate Transporter3 (VGULT3) (Fig. 8E5). E) Two decarboxylase genes, AADC1A (Fig. 8F1) and Decarboxylase Family Protein (Fig. 8F2). F) Amino acid biosynthesis/metabolism genes - Glutamine Amido Transferase (GATase) (Fig. 8G1) and WPP DomainAssociated Protein (Fig. 8G2). The Arabidopsis WPP-domain proteins are developmentally associated with the nuclear envelope and promote cell division [49]. G) Cysteine Desulfurase1 (DES1) (Fig. 8H), which encodes the enzyme L-cysteine desulfhydrase that catalyzes the desulfuration of L-cysteine. The GFP fused to the DES1 promoter was reported to be highly expressed in the AZ of seeds and siliques, and the des 1 mutants exhibited an altered leaf senescence phenotype [50]. H) The gibberellin (GA) receptor gene, GID1L2, which was upregulated in the WT FAZ at $4 \mathrm{~h}$ and peaked at $8 \mathrm{~h}$ after flower removal (Fig. 8I), 


\section{D. $K D 1$ silencing decreases the expression of cell wall modifying genes}

It is well established that cell wall loosening and cell separation occurring in the AZ are controlled by distinct sets of cell wall degrading enzymes. Dissolution of the middle lamella or the shared cell wall in the $A Z$ is a fundamental step in the abscission process. Enzymes and proteins associated with disassembly and modification of the cell wall include PGs, cellulases, endoglucanases, pectin methylesterases, pectate lyases, xyloglucan endotransglucosylase/ hydrolases (XTH), and expansins (EXP) [10, 51-54]. Therefore, the expression pattern of these cell wall modifying enzymes occurring at the late stages of abscission, was used as an additional marker for confirming the effects of $K D 1$ silencing in delaying pedicel abscission.

Our transcriptome analysis revealed a specific upregulation of 28 genes encoding cell wall modifying enzymes in the WT FAZ, whereas in the NAZ the expression of most of them did not change and remained very low during the entire experimental period (Fig. 9A-J). These genes, which belong to 11 families, were downregulated by $K D 1$ silencing, as manifested by their lower or delayed expression in the FAZ of the silenced plants (Fig. 9). Only Cel8, XTH26, and EXP2 genes exhibited some increased expression in the NAZ (Fig. 9B3, C7 and F1). Among the cell wall hydrolyzing enzymes, TAPG4,5, and $X T H 3 a, 3 c, 3 d, 7,10$ were upregulated in the WT FAZ at $4 \mathrm{~h}$ after flower removal, and their expression remained high up to $16 \mathrm{~h}$ (Fig. 9A3, A4, C1-C5). On the other hand, Glucanase, Pectin Esterase, and EXP genes were upregulated only at 8-12 h after flower removal (Fig. 9E1-J). The tomato AZ-specific TAPG genes, TAPG1,2,4,5, were downregulated in the silenced plants compared to the WT (Fig. 9A1-A4). The expression patterns of TAPG1,2,4 in the WT FAZ were identical to their patterns reported previously [2], thereby confirming the microarray results obtained by the tomato AZ-specific microarray chip. Our results further demonstrate that the organ abscission execution, manifested by upregulation of cell wall degrading proteins at phase $\mathrm{C}$ of the abscission process [10,53-55], is a programmed event, in which these proteins were sequentially increased (Fig. 9).

\section{D1. KD1}

\section{Phase D of the abscission process, in which the production of a protective defense layer occurs [10, 53-55], was shown to significantly overlap with the execution phase $\mathrm{C}$ of abscission [23]. We present here only selected data of the numerous defense genes that were specifically upregulated}


in the tomato WT FAZ, and were significantly inhibited in the $K D 1$-silenced plants. Of the set of genes that were specifically and transiently altered in the WT FAZ at $8 \mathrm{~h}$ after flower removal, three genes should be mentioned: Omega6 Fatty Acid Desaturase (Fig. 8J1) and two Lipoxygenase (LOX) genes, Cevi34/LOX (Fig. 8J2) and LOX (Fig. 8J3). Some of the defense-related genes were upregulated in the WT FAZ very early after flower removal (Fig. 10A-E2; marked with red*), while others were upregulated only later on (Fig. 10E3, E4, F1, F2; marked with green*). The expression of all these genes was inhibited in the KD1silenced plants (Fig. 10). These genes are related to abscission, as they were upregulated only in the WT FAZ, in which abscission took place after flower removal. These results confirm the overlapping between phases $C$ and $D$ of the abscission process.

\section{Conclusions}

Based on the results presented in this study, we could further elucidate how KD1 delays pedicel abscission. The present data indicate that KD1 is a master regulator of tomato pedicel abscission, as the expression of important regulatory genes was modified in the FAZ of the KD1-silenced plants at $4 \mathrm{~h}$ after flower removal, i.e. at the early stage of the abscission process, compared to the WT FAZ. This led to the inhibition of pedicel abscission, as summarized in Figure 11. Moreover, it should be noted that KD1 expression decreased in the silenced plants already at zero time, which led to the modified expression of regulatory genes before flower removal (Fig. 11A). These early modified regulatory genes included epigenetic modifiers, TFs, post translation regulators, and antioxidative defense factors. Some of them might directly affect auxin homeostasis and transport, resulting in slowing down auxin depletion in the FAZ, which leads to inhibition of the acquisition of the competence of the FAZ to respond to the ethylene signaling. The changes in gene expression occurring at $4 \mathrm{~h}$ after flower removal (Fig. 11B) might result either from a direct effect of KD1 silencing, or from the changes in gene expression occurring at zero time, prior to abscission induction (Fig. 11A). The above data suggest a possible mode of action for the manipulation of auxin levels and response obtained following KD1 silencing, which finally leads to inhibition of pedicel abscission. 
The effects of KD1 silencing, which result in the inhibited abscission phenotype, include also indirect effects leading to downregulation of genes involved in abscission execution and defense. Thus, the inhibited expression of exocytosis and protein transporters such as AAA-ATPase and Syntaxin, which inhibited the export of Golgi-derived vesicles containing cell wall degrading enzymes across the plasma membrane of AZ cells, might have an important role in the inhibited abscission phenotype of the KD1silenced plants. It seems therefore, that the inhibitory effect of $K D 1$ silencing on flower pedicel abscission is not limited to manipulation of auxin levels and response as previously reported, but it probably also operates via alteration of other regulatory pathways that delay the acquisition of the competence of the FAZ cells to respond to ethylene signaling and abscission execution (Fig. 11B).

Since KD1 belongs to the class I KNOX family, its role in organ abscission is in agreement with the various regulatory roles of class I KNOX family proteins, which were found to regulate several genes involved in biosynthesis and signal transduction of various plant hormones, TFs, and lignin synthesis. Taken together, the present study shades light on the role of KD1 as a master regulator of various signaling factors and regulatory genes involved in organ abscission processes, in addition to its welldocumented involvement in leaf development, shoot apical meristem maintenance, and differentiation of flower meristems.

\section{Methods}

\section{Plant material and abscission induction treatments}

The experiments were performed with tomatoSolanum lycopersicum, cv. 'New Yorker') plants, grown from seeds obtained from the Tomato Genetics Resource Center, University of California, Davis, USA. All plants were grown in a greenhouse located in The Volcani Center, Israel, under a controlled temperature of $25^{\circ} \mathrm{C}$ and natural daylight. The flower abscission experiments were carried out with plants grown in 10-L pots. The inflorescences of both WT and the KD1-antisense transgenic lines were harvested from 4-month-old plants as previously described $[2,7]$. The experiment protocols and pedicel abscission assays were performed in a controlled observation room maintained at $20^{\circ} \mathrm{C}$ and 60 to $70 \%$ relative humidity with continuous light of $14 \mu \mathrm{mol} \mathrm{m}{ }^{-2} \mathrm{~s}^{-1}$, as previously described $[2,7,23]$. The number of abscised pedicels was monitored daily by touching the distal side of the FAZ, for calculating the accumulated percentage of pedicel abscission.

Leaf abscission experiments were carried out with plants grown in $576 \mathrm{~cm}^{3}$ pots, which had 6 to 8 true leaves per plant. For abscission induction, the leaves of the WT and the KD1-silencedtransgenic plants were debladed for auxin depletion, and $48 \mathrm{~h}$ after leaf deblading, the plants were treated with $10 \mu \mathrm{L} \mathrm{L}^{-1}$ ethylene for $24 \mathrm{~h}$ at $23^{\circ} \mathrm{C}$, as previously described [22]. After the ethylene treatment, the plants were transferred to a controlled observation room, and the accumulated percentage of petiole abscission was monitored at specified time intervals (during days 1 to 10) for each true leaf at four positions above the cotyledons. The kinetics of flower and leaf abscission was determined in three different experiments, 
using 10-12 plants for each line, with similar results, and the results of one representative experiment are presented.

\section{Vector construction and plant transformation}

The generation of the TAPG4::antisense KD1 transgenic plants was basically performed as previously described [6]. Briefly, a 2379-bp fragment of the AZ-specific TAPG4 promoter from tomato genomic DNA and a 227-bp fragment of the KD1 gene from tomato cDNA were amplified, and then sub-cloned into the modified binary vector GSA1285 in an antisense orientation. We used the primers 5'TCTCAGCTCAGTGAACTCATGG-3' and 5'-TTGTGGCAATCTAGCCA-TACAT-3' for the KD1 amplification, introduced the plasmid constructs into Agrobacterium tumefaciens (LBA4404), and transformed the tomato 'New Yorker' as previously described [56]. In this way we generated 10 independent transgenic lines, from which we selected two representative transgenic lines (lines A and E, T4 generation) as previously reported [6], for further analysis.

\section{Gene expression profiling}

For expression and microarray studies, we used samples of the FAZ and the NAZ of the WT and the FAZ of TAPG4:::antisence $K D 1$ line $\mathrm{E}$, collected in duplicates at various time points $(0,4,8,12,16$, and $20 \mathrm{~h}$ after flower removal). The RNA was extracted, treated with DNase, processed and checked for its quality, using the Agilent platform (Agilent, Palo Alto, CA), as previously described [7, 22].

\section{Microarray}

The experimental procedures for microarray labeling, hybridization, and scanning were performed as previously detailed [7], using the AZ-specific microarray chip, AMADID: 043310 (Genotypic Technology, Pvt. Ltd, Bangalore, India) for hybridization of the labeled cRNA samples [22]. We used the Feature Extraction software of Agilent $\mathrm{V}-\mathbf{1 1 . 5}$ for the data extraction from images. The analysis of the microarray data, using duplicate samples for each time point, to identify significant genes that were up- and downregulated within the group of samples, was basically performed as previously detailed [7].

\section{Validation of gene expression by qRT-PCR}

All the procedures for validation of gene expression were performed as previously detailed [7], according to the primers sequences, amplicon length, and annealing ( $\mathrm{Tm}$ ) presented in Additional file 8: Table S7. These primers matched the microarray probes, and the qRT-PCR and microarray analyses were performed with the same RNA samples, as previously described [22]. ACTIN was used as the reference gene for determination of the relative expression levels of the identified genes. 


\section{Sequence deposition}

The data for the TAPG::antisense KD1 FAZ samples (12 arrays) were submitted under the Gene Expression Omnibus database NCBI-GEO accession id: GSE64564. The microarray data for WT (cv. 'New Yorker') FAZ and NAZ samples (12 arrays each) were submitted as previously detailed [7] under accession id: GSE64221. The data will be released for public access upon acceptance of the manuscript.

\section{List Of Abbreviations}

AAA ${ }^{+}$-ATPases: ATPases Associated with various cellular Activities; ACC: 1-Amino-cyclopropane-1carboxylic acid; ACO: ACC oxidase; AZ: Abscission zone; CaM: Calmodulin; ERF: Ethylene responsive factor; FAZ: Flower AZ; GA: Gibberellin; GO: Gene ontology; KD1: Knotted1-like Homeobox protein; NAZ: Non-AZ; RNA-Seq: RNA sequencing; qRT-PCR: Quantitative reverse transcription polymerase chain reaction; TAPG4: Tomato abscission polygalacturonase4; TF: Transcription factor; WT: Wild type; XTH: Xyloglucan endotransglucosylase/hydrolase.

\section{Declarations}

\section{Ethics approval and consent to participate}

Not applicable.

\section{Consent for publication}

Not applicable.

\section{Availability of data and materials}

All data generated or analysed during this study are included in this published article and its Additional files. Any other informationis available from the corresponding author upon request.

\section{Competing interests}

The authors declare that they have no competing interests.

\section{Funding}

This work was supported by the United States-Israel Binational Agricultural Research and Development Fund (BARD) [grant number US -4571-12C to SM, CZJ. and SPH], and by the Chief Scientist of the Israeli 


\section{Authors' contributions}

SS and SM conceived the original screening and research plans. SM, SPH, and JR supervised the experiments. SS performed most of the experiments and analyzed the data. CM and CZJ prepared the constructs and produced the silenced plants. BK and ShS provided technical assistance to SS. SM and SPH conceived the project and wrote the article with contributions of all the authors. JR and MSR supervised, critically revised and complemented the writing. All authors have read and approved the final version of the manuscript.

\section{Acknowledgments}

Contribution from the ARO, The Volcani Center, Rishon Lezion, Israel.

Srivignesh Sundaresan would like to thank the Indian Council of Agricultural Research for providing him with an International Fellowship (ICAR-IF) to support his PhD studies.

We acknowledge the Genotypic Technology Private, Ltd. Bangalore, India, for the microarray processing and the data analysis reported in this publication.

\section{References}

1. Meir S, Sundaresan S, Riov J, Agarwal I, Philosoph-Hadas S. Role of auxin depletion in abscission control. Stewart Postharvest Rev. 2015;11(2):1-15. doi:10.2212/spr.2015.2.2.

2. Meir S, Philosoph-Hadas S, Sundaresan S, Selvaraj KS, Burd S, Ophir R, Kochanek B, Reid MS, Jiang $\mathrm{C}-\mathrm{Z}$, Lers A. Microarray analysis of the abscission-related transcriptome in the tomato flower abscission zone in response to auxin depletion. Plant Physiol. 2010;154:1929-1956. doi:10.1104/pp.110.160697.

3. Nakano T, Fujisawa M, Shima Y, Ito Y. Expression profiling of tomato pre-abscission pedicels provides insights into abscission zone properties including competence to respond to abscission signals. BMC Plant Biol. 2013;13:40. doi:10.1186/1471-2229-13-40.

4. Nakano T, Fujisawa M, Shima $Y$, Ito $Y$. The AP2/ERF transcription factor SIERF52 functions in flower pedicel abscission in tomato. J Exp Bot. 2014;65:3111-3119. doi: 10.1093/jxb/eru154.

5. Wang X, Liu D, Li A, Sun X, Zhang R, Wu L. Liang Y, Mao L. Transcriptome analysis of tomato flower pedicel tissues reveals abscission zone-specific modulation of key meristem activity genes. PLoS One. 2013;8:e55238. doi:10.1371/journal.pone.0055238.

6. Ma C, Meir S, Xiao L, Tong J, Liu Q, Reid, MS, Jiang C-Z. A KNOTTED1-LIKE HOMEOBOX protein regulates abscission in tomato by modulating the auxin pathway. Plant Physiol. 2015;167:844-853. 
doi:10.1104/pp.114.253815.

7. Sundaresan S, Philosoph-Hadas S, Ma C, Jiang C-Z, Riov, J, Mugasimangalam R, Kochanek B, Salim $\mathrm{S}$, Reid MS, Meir S. The Tomato Hybrid Proline-rich Protein regulates the abscission zone competence to respond to ethylene signals. Hort Res. 2018;5:28. doi:10.1038/s41438-018-0033-2.

8. Shi CL, Stenvik GE, Vie AK, Bones AM, Pautot V, Proveniers M, Aalen RB, Butenko MA. Arabidopsis class I KNOTTED-like homeobox proteins act downstream in the IDA-HAE/HSL2 floral abscission signaling pathway. Plant Cell. 2011;23:2553-2567. doi:10.1105/tpc.111.084608.

9. Liljegren SJ. Organ abscission: exit strategies require signals and moving traffic. Curr Opin Plant Biol. 2012;15:670-676. doi:10.1016/j.pbi.2012.09.012.

10. Estornell, LH, Agusti J, Merelo P, Talon M, Tadeo FR. Elucidating mechanisms underlying organ abscission. Plant Sci. 2013;199-200:48-60. doi:10.1016/j.plantsci.2012.10.008.

11. Yoon J, Cho LH, Wai Antt H, Koh HJ, An G. KNOX protein OSH15 induces grain shattering by repressing lignin biosynthesis genes. Plant Physiol. 2017;174:312-325.

12. Kimura S, Koenig D, Kang J, Yoong FY, Sinha N. Natural variation in leaf morphology results from mutation of a novel KNOX gene. Curr Biol. 2008;18:672-677.

13. Magnani E, Hake S. KNOX lost the OX: the Arabidopsis KNATM gene defines a novel class of KNOX transcriptional regulators missing the homeodomain. Plant Cell. 2008;20:875-887.

14. Peng J, Yu J, Wang H, Guo Y, Li G, Bai G, Chen R. Regulation of compound leaf development in Medicago truncatula by Fused Compound Leaf1, a class M KNOX gene. Plant Cell. 2011; 23:39293943.

15. Tsuda K, Ito Y, Sato Y, Kurata N. Positive autoregulation of a KNOX gene is essential for shoot apical meristem maintenance in rice. Plant Cell. 2011;23:4368-4381.

16. Tsuda K, Abraham-Juarez MJ, Maeno A, Dong Z, Aromdee D, Meeley R, Shiroishi T, Nonomura K, Hake S. KNOTTED1 cofactors, BLH12 and BLH14, regulate internode patterning and vein anastomosis in maize. Plant Cell. 2017;29:1105-1118. doi: 10.1105/tpc.16.00967.

17. Tsuda K, Hake S. Diverse functions of KNOX transcription factors in the diploid body plan of plants. Curr Opin Plant Biol. 2015;27; 91-96.

18. Roth O, Alvarez JP, Levy M, Bowman JI, Ori N, Shani E. The KNOXI transcription factor SHOOT MERISTEMLESS regulates floral fate in Arabidopsis. Plant Cell. 2018;30:1309-1321.

19. Koenig D, Bayer E, Kang J, Kuhlemeier C, Sinha N. Auxin patterns Solanum lycopersicum leaf morphogenesis. Development. 2009;136:2997-3006.

20. Bolduc N, Yilmaz A, Mejia-Guerra MK, Morohashi K, O'Connor D, Grotewold E, Hake S. Unraveling the KNOTTED1 regulatory network in maize meristems. Genes Dev. 2012;26: 1685-1690.

21. Hong SB, Sexton R, Tucker ML. Analysis of gene promoters for two tomato polygalacturonases expressed in abscission zones and the stigma. Plant Physiol. 2000;123: 869-881.

22. Sundaresan S, Philosoph-Hadas S, Riov J, Mugasimangalam R, Kuravadi NA, Kochanek B, Salim S, Tucker ML, Meir S. De novo transcriptome sequencing and development of abscission zone-specific 
microarray as a new molecular tool for analysis of tomato organ abscission. Front Plant Sci. 2016;6. doi:10.3389/fpls.2015.01258.

23. Kim J, Sundaresan S, Philosoph-Hadas S, Yang R, Meir S, Tucker ML. Examination of the abscissionassociated transcriptomes for soybean, tomato, and arabidopsis highlights the conserved biosynthesis of an extensible extracellular matrix and boundary layer. Front Plant Sci. 2015;6:1109. doi:10.3389/fpls.2015.01109.

24. Li Y, Li H. Many keys to push: diversifying the 'readership' of plant homeodomain fingers. Acta Biochim Biophys Sin (Shanghai). 2012;44:28-39. doi:10.1093/abbs/gmr117.

25. Gil-Amado JA, Gomez-Jimenez MC. Transcriptome analysis of mature fruit abscission control in olive. Plant Cell Physiol. 2013;54:244-269. doi:10.1093/pcp/pcs179.

26. DeFalco TA, Bender KW. Breaking the code: $\mathrm{Ca} 2+$ sensors in plant signalling. Biochem J. 2009;425:27-40.

27. Batistič O, Kudla J. Analysis of calcium signaling pathways in plants. Biochem Biophys Acta. 2012;1820:1283-1293.

28. Agusti J, Gimeno J, Merelo P, Serrano R, Cercos M, Conesa, A, Talon M, Tadeo FR. Early gene expression events in the laminar abscission zone of abscission-promoted citrus leaves after a cycle of water stress/rehydration: involvement of CitbHLH1. J Exp Bot. 2012;63:6079-6091. doi:10.1093/jxb/ers270.

29. Li C, Wang Y, Ying P, Ma W, Li J. Genome-wide digital transcript analysis of putative fruitlet abscission related genes regulated by ethephon in litchi. Front Plant Sci. 2015;6:502. doi: 10.3389/fpls.2015.00502.

30. Lipka V, Kwon C, Panstruga R. SNARE-ware: the role of SNARE-domain proteins in plant biology. Annu Rev Cell Dev Biol. 2007;23:147-174. doi:10.1146/annurev.cellbio.23.090506. 123529.

31. Sexton R, Hall JL. Fine structure and cytochemistry of the abscission zone cells of Phaseolus leaves: I. Ultrastructural changes occurring during abscission. Annals Bot. 1974;38:849-854.

32. Sexton R, Jamieson GGC, Allan MHIL. An ultrastructural study of abscission zone cells with special reference to the mechanism of enzyme secretion. Protoplasma. 1977;91:369-387. doi: 10.1007/bf01291927.

33. Corbacho J, Romojaro F, Pech JC, Latche A, Gomez-Jimenez MC. Transcriptomic events involved in melon mature-fruit abscission comprise the sequential induction of cell-wall degrading genes coupled to a stimulation of endo and exocytosis. PLoS One. 2013;8:e58363. doi: 10.1371/journal.pone.0058363.

34. Andolfo G, Ruocco M, Donato AD, Frusciante L, Lorito M, Scala F, Ercolano MR. Genetic variability and evolutionary diversification of membrane $A B C$ transporters in plants. BMC Plant Biol. 2015;15:51. doi:10.1186/s12870-014-0323-2.

35. Barlowe C. Traffic COPs of the early secretory pathway. Traffic 2000;1:371-377.

36. Hull AK, Vij R, Celenza JL. Arabidopsis cytochrome P450s that catalyze the first step of tryptophandependent indole-3-acetic acid biosynthesis. Proc Natl Acad Sci. 2000;97:2379-2384. doi: 
10.1073/pnas.040569997.

37. Ben-Naim O, Eshed R, Parnis A, Teper-Bamnolker P, Shalit A, Coupland G, Samach A, Lifschitz E. The CCAAT binding factor can mediate interactions between CONSTANS-like proteins and DNA. Plant J. 2006;46:462-476. doi:10.1111/j.1365-313X.2006.02706.x.

38. Wenkel S, Turck F, Singer K, Gissot L, Le Gourrierec J, Samach A, Coupland G. CONSTANS and the CCAAT box binding complex share a functionally important domain and interact to regulate flowering of Arabidopsis. Plant Cell. 2006;18:2971-2984. doi:10.1105/tpc. 106.043299.

39. Shi X, Gupta S, Lindquist IE, Cameron CT, Mudge J, Rashotte AM. Transcriptome analysis of cytokinin response in tomato leaves. PLoS One. 2013;8:e55090. doi:10.1371/ journal.pone.0055090.

40. Ponting CP. Domain homologues of dopamine beta-hydroxylase and ferric reductase: roles for iron metabolism in neurodegenerative disorders? Hum Mol Genet. 2001;10:1853-1858.

41. Iyer LM, Anantharaman V, Aravind L. The DOMON domains are involved in heme and sugar recognition. Bioinformatics. 2007;23:2660-2664. doi:10.1093/bioinformatics/btm411.

42. Verelst W, Asard H. A phylogenetic study of cytochrome b561 proteins. Genome Biol. 2003;4: R38. doi:10.1186/gb-2003-4-6-r38.

43. Poovaiah B, Rasmussen $H$, Bukovac M. Histochemical localization of enzymes in the abscission zones of maturing sour and sweet cherry fruit. J Amer Soc Hort Sci 1973;98:16-18.

44. Poovaiah BW, Rasmussen $\mathrm{H}$. Localization of dehydrogenase and acid phosphatase in the abscission zone of bean leaves. Am J Bot. 1974;68-73.

45. Gilliland MG, Bornman $\mathrm{CH}$, Addicott FT. Ultrastructure and acid phosphatase in pedicel abscission of Hibiscus. Am J Bot. 1976;63:925-935.

46. Tan X, Calderon-Villalobos LI, Sharon M, Zheng C, Robinson CV, Estelle M, Zheng N. Mechanism of auxin perception by the TIR1 ubiquitin ligase. Nature. 2007;446:640-645. doi: 10.1038/nature05731.

47. White SR, Lauring B. AAA+ ATPases: achieving diversity of function with conserved machinery. Traffic. 2007;8:1657-1667. doi:10.1111/j.1600-0854.2007.00642.x.

48. Bussemer J, Chigri F, Vothknecht UC. Arabidopsis ATPase family gene 1-like protein 1 is a calmodulin-binding AAA+-ATPase with a dual localization in chloroplasts and mitochondria. FEBS J. 2009;276:3870-3880. doi:10.1111/j.1742-4658.2009.07102.x.

49. Patel S, Rose A, Meulia T, Dixit R, Cyr RJ, Meier I. Arabidopsis WPP-domain proteins are developmentally associated with the nuclear envelope and promote cell division. Plant Cell. 2004;16:3260-3273. doi:10.1105/tpc.104.026740.

50. Laureano-Marin AM, Garcia I, Romero LC, Gotor C. Assessing the transcriptional regulation of Lcysteine desulfhydrase1 in Arabidopsis thaliana. Front Plant Sci. 2014;5:683. doi:10.3389/fpls.2014.00683.

51. Lashbrook CC. Functional genomic approaches to abscission. Stewart Postharvest Rev. 2009;5:1-7. doi:10.2212/spr.2009.1.4. 
52. Lashbrook CC, Cai S. Cell wall remodeling in Arabidopsis stamen abscission zones: temporal aspects of control inferred from transcriptional profiling. Plant Signal Behav. 2008;3:733-736.

53. Patterson SE. Cutting loose. Abscission and dehiscence in Arabidopsis. Plant Physiol. 2001;126:494-500.

54. Roberts JA, Elliott KA, Gonzalez-Carranza ZH. Abscission, dehiscence, and other cell separation processes. Annu Rev Plant Biol. 2002;53:131-158. doi:10.1146/annurev.arplant. 53.092701.180236.

55. Kim J. Four shades of detachment: regulation of floral organ abscission. Plant Signal Behav. 2014;9:e976154. doi:10.4161/15592324.2014.976154.

56. Fillatti JJ, Kiser J, Rose R, Comai L. Efficient transfer of a glyphosate tolerance gene into tomato using a binary Agrobacterium tumefaciens vector. Nat Biotech. 1987;5:726-730.

\section{Tables}

Table 1: Transcriptome responses of the FAZ tissues at various time points after flower removal in the transgenic (TAPG4::antisense KD1) line compared to the WT. The data represent the total numbers of differentially expressed transcripts (fold changes: downregulated $\leq-2$; upregulated $\geq 2$ ) at different time points after flower removal during the abscission process.

\begin{tabular}{|c|c|c|}
\hline $\begin{array}{c}\text { Time after flower removal } \\
(\mathrm{h})\end{array}$ & $\begin{array}{c}\text { Number of differentially expressed transcripts in } \\
\text { the FAZs of TAPG4::antisense KD1 vs WT plants }\end{array}$ \\
\hline & Upregulated & Downregulated \\
\hline 0 & 64 & 120 \\
\hline 4 & 76 & 126 \\
\hline 8 & 96 & 319 \\
\hline 12 & 111 & 58 \\
\hline 16 & 304 & 307 \\
\hline 20 & 175 & 76 \\
\hline
\end{tabular}

\section{Figures}




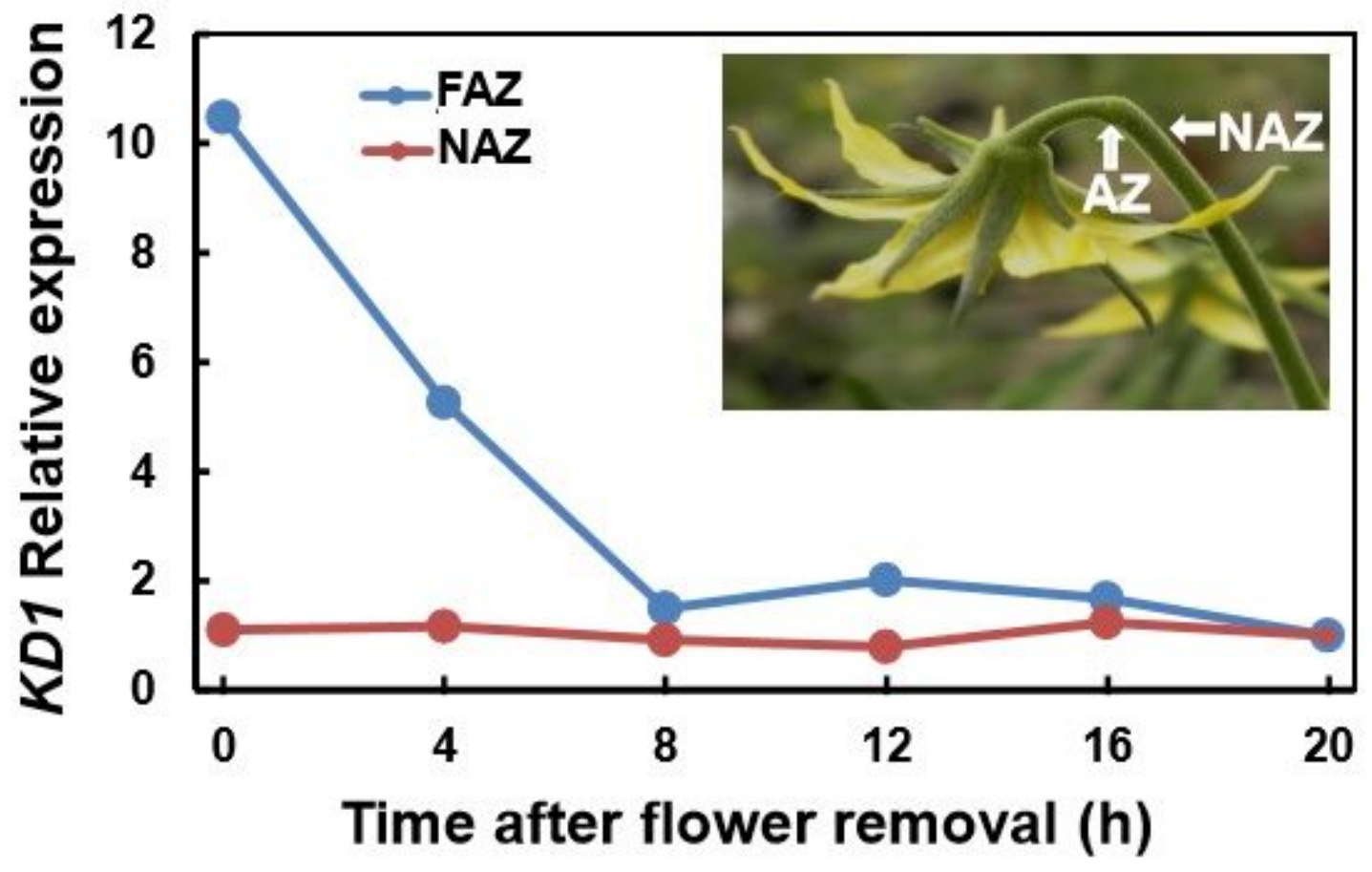

Figure 1

Effect of flower removal on the expression of KD1 in the WT FAZ and NAZ. The KD1 expression was determined by qRT-PCR at $0,4,8,12,16$, and $20 \mathrm{~h}$ after flower removal. The relative quantification of the gene expression level by the qPCR assay was determined by the comparative CT method 2- $\Delta \mathrm{CT}$, using Actin as a reference gene. The $\Delta \mathrm{CT}$ values were compared to the 20-h $\Delta \mathrm{CT}$ value for KD1 to generate 2$\Delta \Delta C T$ values. The results are means of three biological replicates \pm SD. Inset, localization of the FAZ and NAZ along the flower pedicel, from which tissue samples were taken. 


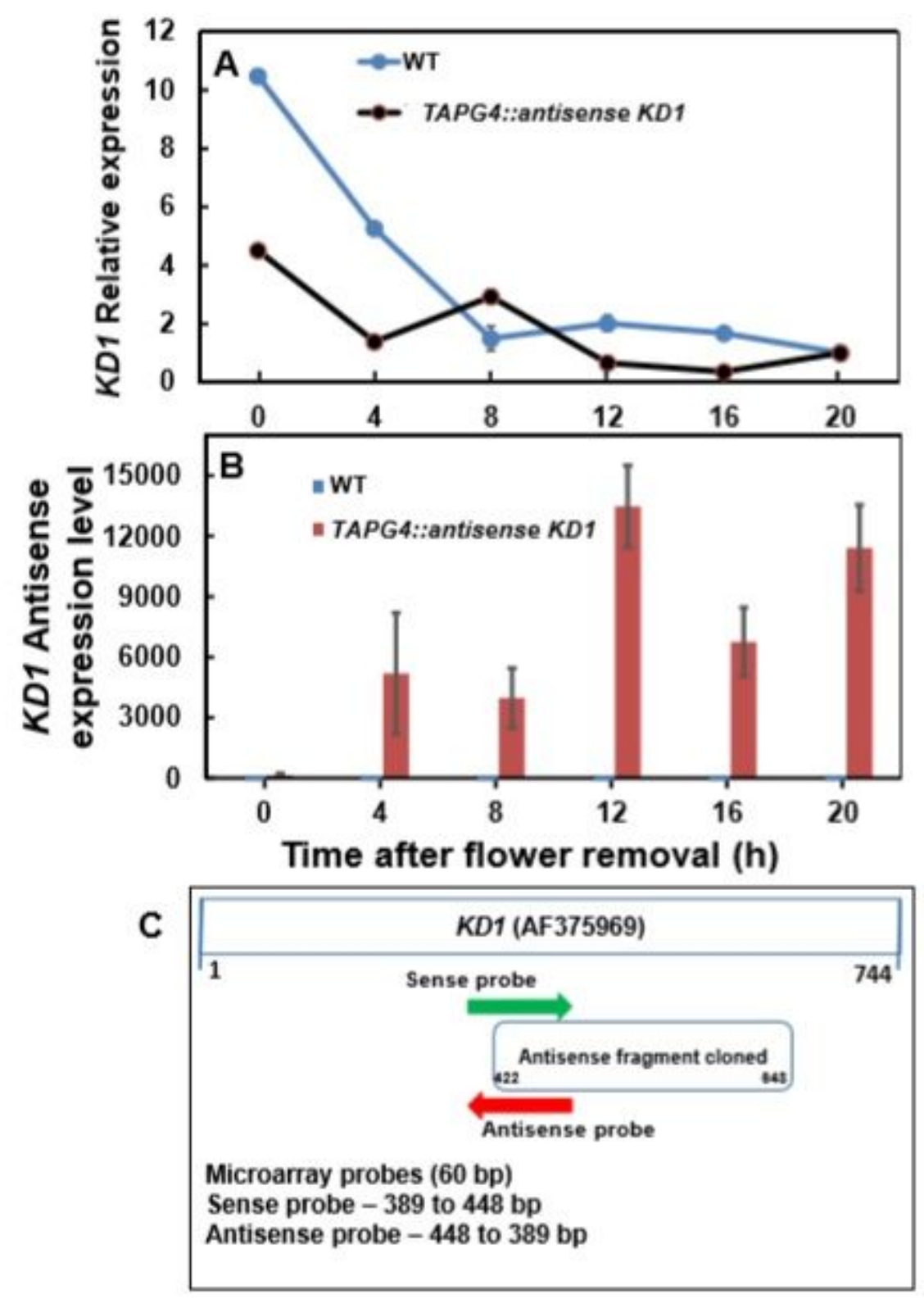

Figure 2

Effect of flower removal on the qRT-PCR expression levels of KD1 (A) and on the array-measured expression levels of the antisense probe of KD1 (B) in the FAZs of the WT and TAPG4::antisense KD1 line $E$. The schematic illustration of the sense and antisense microarray probes spanning the KD1 gene is presented (C). The qRT-PCR assay was performed as detailed in Figure 1. The fragment (422-648th bp) of the KD1 gene (AF375969) was cloned for antisense into the vector. The sense probe from the microarray spans the region of 389-448th bp, and the antisense probe from the microarray spans the region of 448389th bp. 

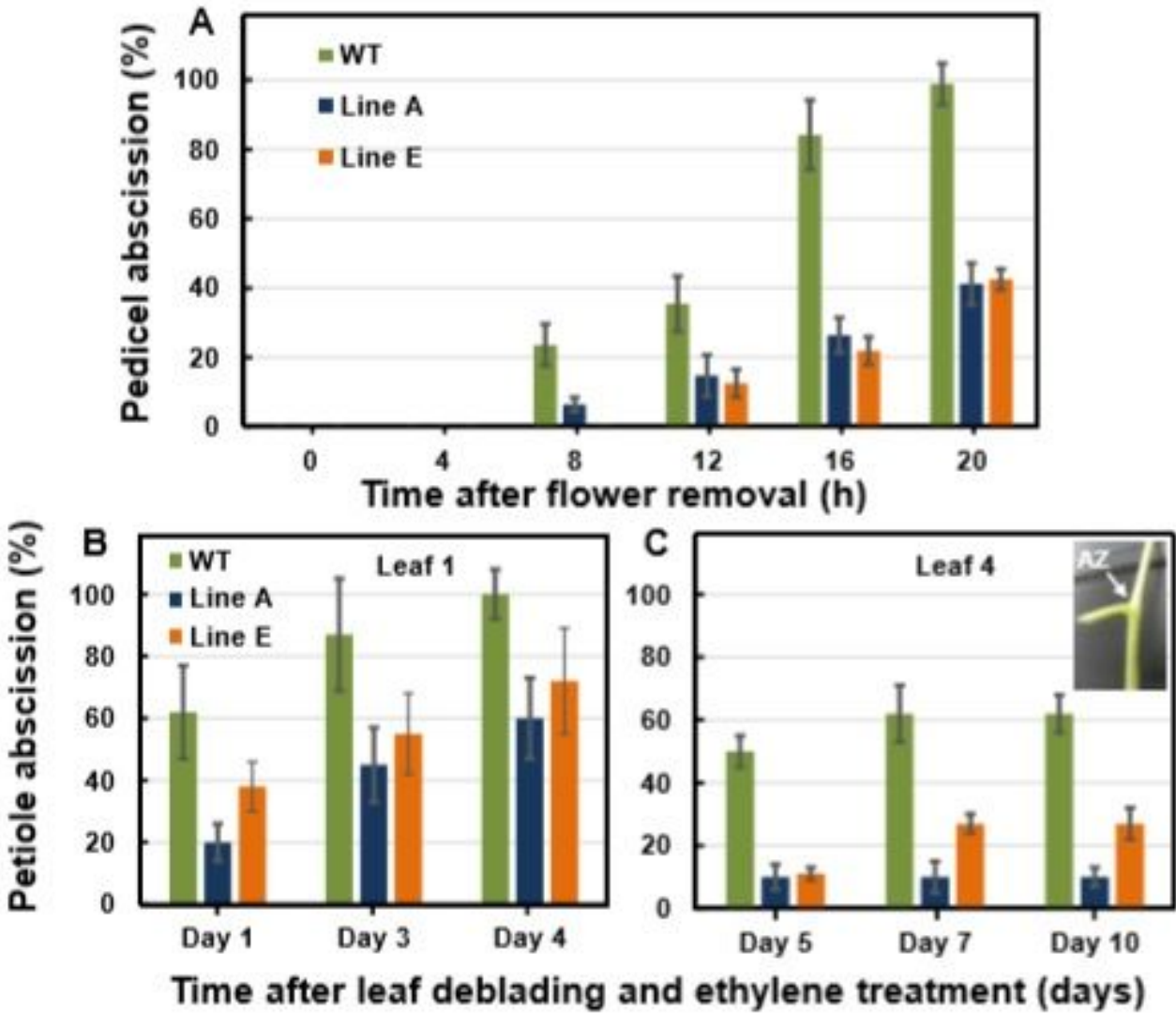

\section{Figure 3}

Effects of TAPG4::antisense KD1 silencing on the abscission kinetics of flower pedicels (A) and petioles of leaf 1 (B) and leaf 4 (C). The accumulated percentage of pedicel abscission was monitored at $0,4,8$, 12,16 , and $20 \mathrm{~h}$ following flower removal. Petiole abscission was induced in intact plants by leaf deblading followed by treatment with $10 \mu \mathrm{L}$.L-1 ethylene for $24 \mathrm{~h}$ applied $48 \mathrm{~h}$ after leaf deblading. The accumulated percentage of petiole abscission was monitored during days 1 to 10 for true leaf positions 1 and 4 above the cotyledons. The results are means of three experiments $\pm S D(n=40$ explants for flowers and at least 10 plants for leaves in each experiment). $C$ - Inset, the location of the leaf AZ is indicated by the white arrow. 

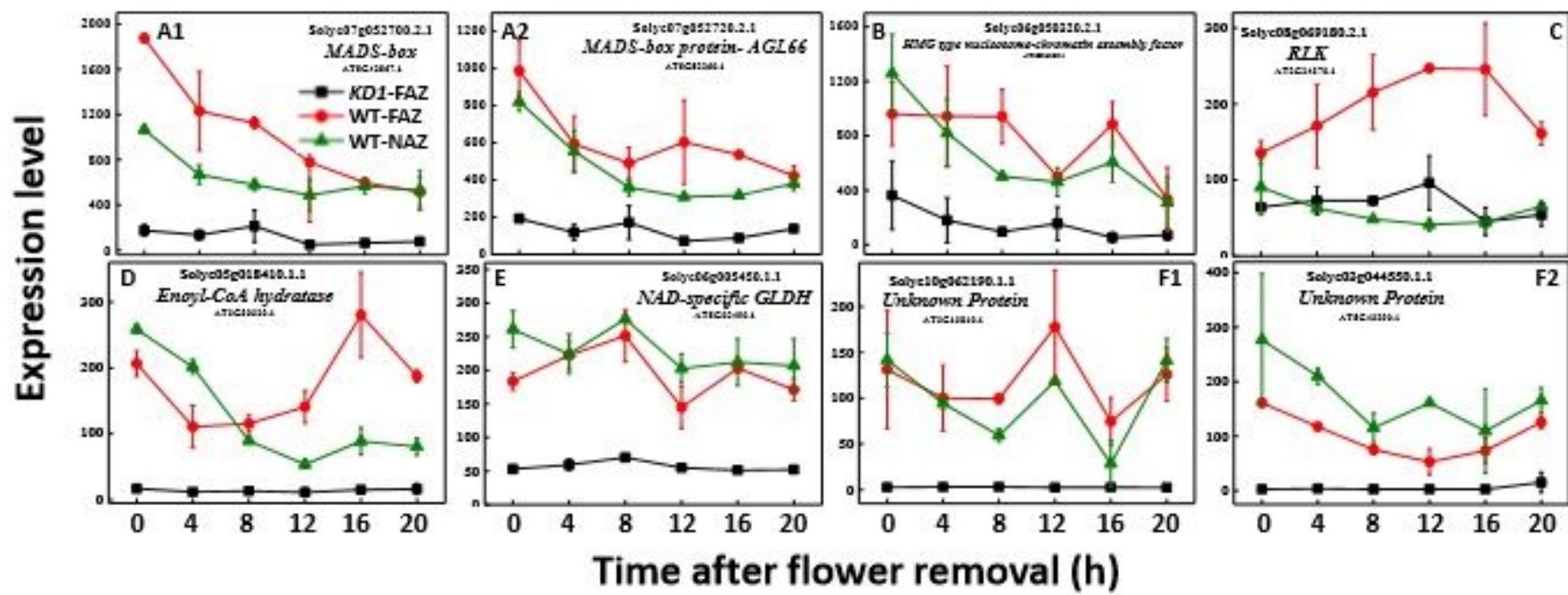

Time after flower removal (h)

Figure 4

Effect of antisense silencing of KD1 on the kinetics in array-measured expression levels of genes that were specifically downregulated in the FAZ of TAPG4::antisense KD1-silenced plants, before (at zero time) and after flower removal compared to the FAZ of WT plants. TAPG4::antisense KD1 silenced line E was used. Expression levels were measured for the following genes: MADS-box transcription factor 1 (A1) and MADS-box protein-AGL66 (A2); High Mobility Group (HMG) type nucleosome/chromatin assembly factor (B); Receptor-Like protein Kinase (RLK) (C); Enoyl-CoA Hdratase (D); NAD-specific Glutamate Dehydrogenase (GLDH) (E); and Unknown Protein genes (F1, F2). Transcript identities are indicated in the graphs by their gene ID and their Arabidopsis (At) gene number and/or their nucleotide accession number. The results are means of two biological replicates \pm SD. The Red and Green lines represent the gene expression in the FAZ and NAZ of the WT plants, and the Black lines represent the gene expression in the FAZ of KD1-silenced plants, respectively. 

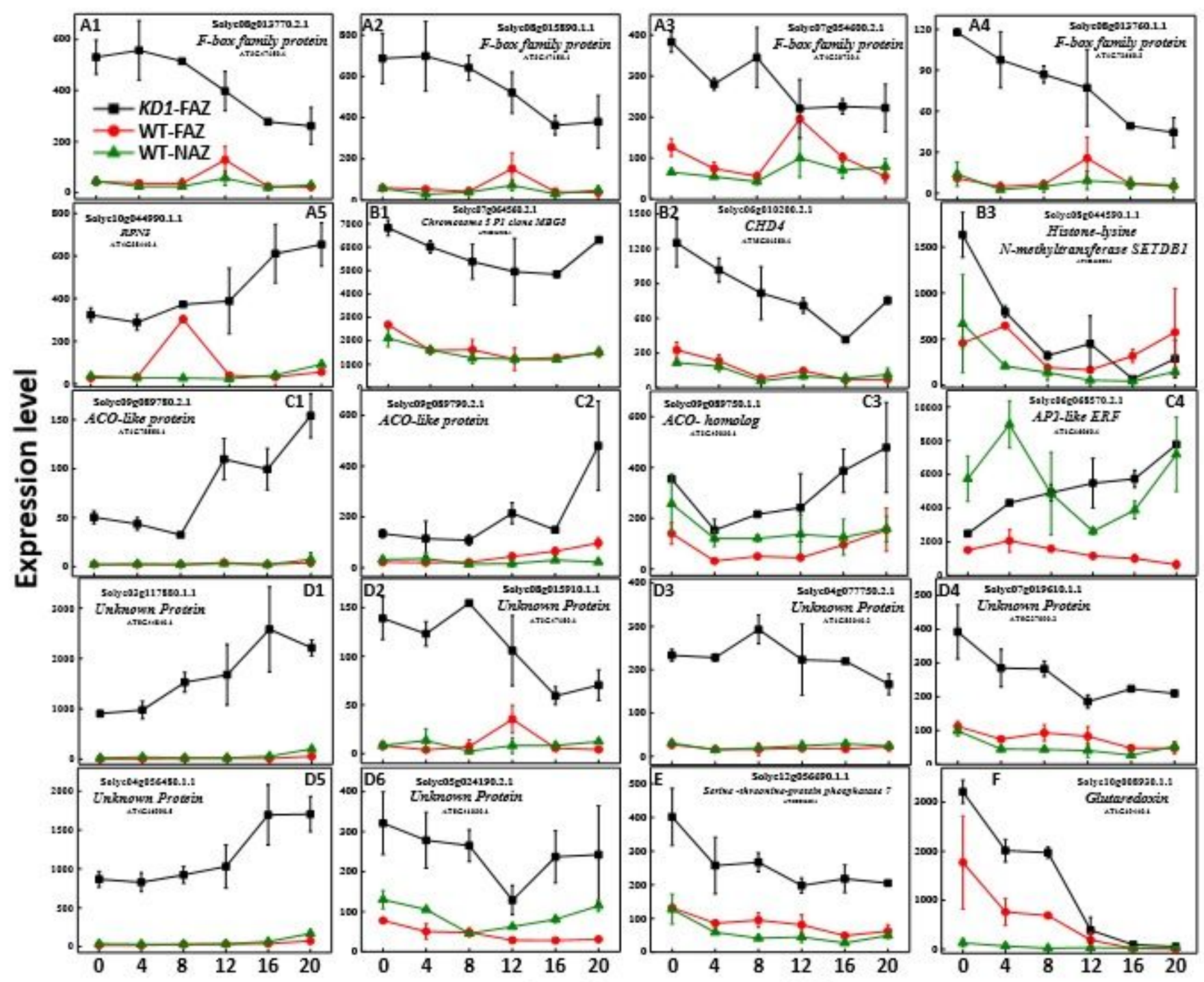

Time after flower removal (h)

\section{Figure 5}

Effect of antisense silencing of KD1 on the kinetics in array-measured expression levels of genes that were specifically upregulated in the FAZ of TAPG4::antisense KD1-silenced plants, before (at zero time) and after flower removal, compared to the FAZ of WT plants. Expression levels were measured for the following genes: F-box family proteins (A1-A4), and 26S proteasome non-ATPase regulatory subunit3 (RPN3) (A5); genomic DNA chromosome 5P1 clone MBG8 (B1); Chromodomain Helicase DNA-Binding protein4 (CHD4) (B2), and Histone-lysine N-methyltransferase SETDB1 (B3); two 1-Aminocyclopropane-1Carboxylate Oxidase (ACO)-like protein genes (C1, C2), ACO-homologue (C3), and AP2-like-Ethylene Response Factor (ERF) (C4); six Unknown Protein genes (D1-D6); Serine-threonine-protein phosphatase7 $(E)$; and Glutaredoxin $(F)$. All other details are as described in Figure 4. 


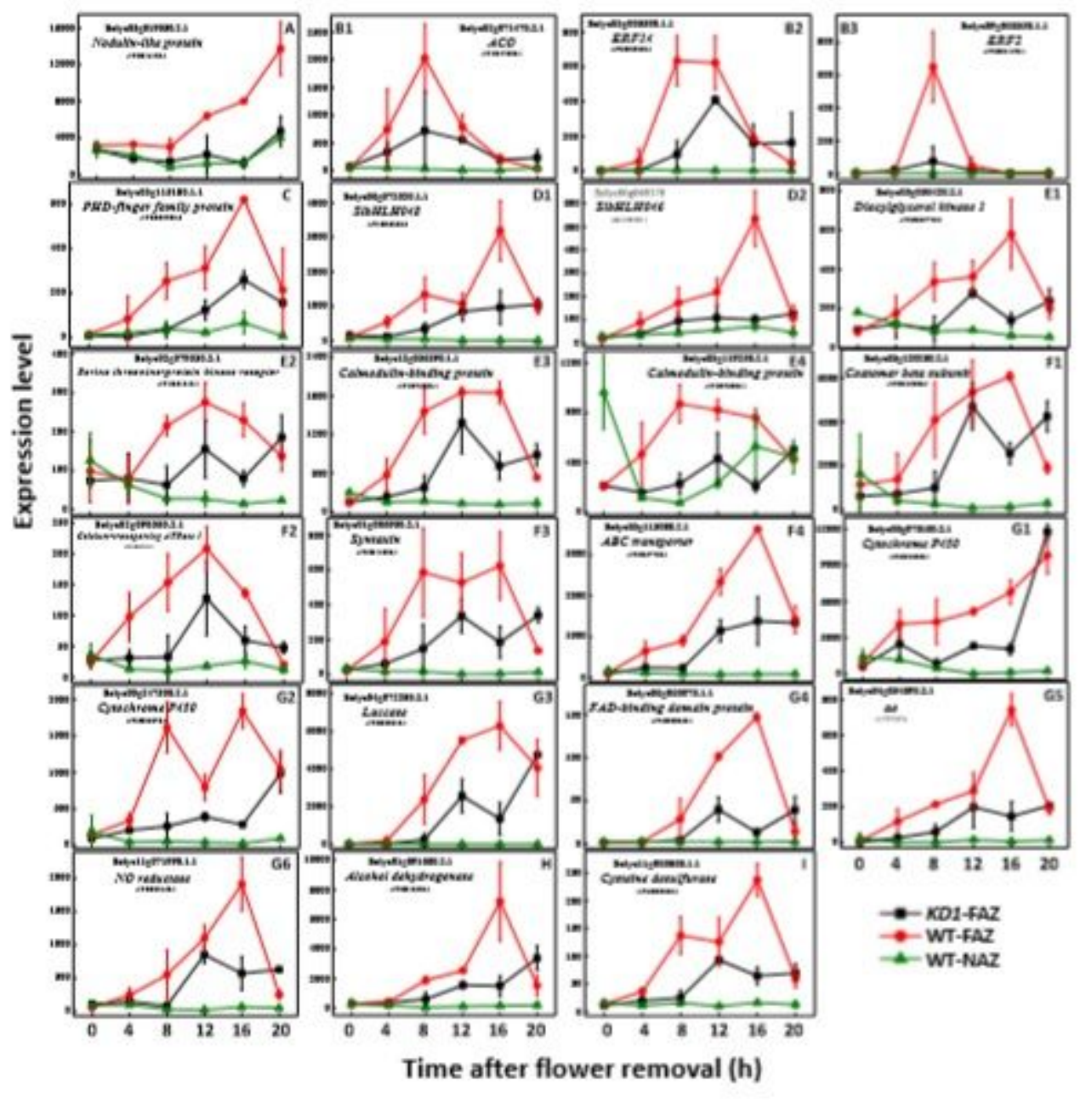

Figure 6

Effect of antisense silencing of KD1 on the kinetics in array-measured expression levels of genes that were specifically modified in the WT FAZ plants at 4 or $8 \mathrm{~h}$ after flower removal. Expression levels were measured for the following genes: Nodulin-like protein (A); 1-Aminocyclopropane-1-Carboxylate Oxidase1 (AC01) (B1); Ethylene-Responsive Factor14 (ERF14) (B2); ERF2 (B3); PHD-finger family protein (C); Solanum lycopersicum Basic Helix-Loop-Helix048 (SIbHLH048) (D1), SlbHLH046 (D2); Diacylglycerol Kinase1 (E1); Serine/threonine-protein kinase receptor (E2); two Calmodulin-Binding protein genes (E3, E4); Coatomer beta subunit (F1), Calcium-transporting ATPase1 (F2), Syntaxin (F3), and ABC transporter (F4); two Cytochrome P450 genes (G1, G2), Laccase (G3), FAD-binding domain-protein (G4), Ascorbate Oxidase (AO) (G5), and Nitric Oxide (NO) reductase (G6); Alcohol Dehydrogenase (H); and Cysteine Desulfurase (I). All other details are as described in Figure 4. 


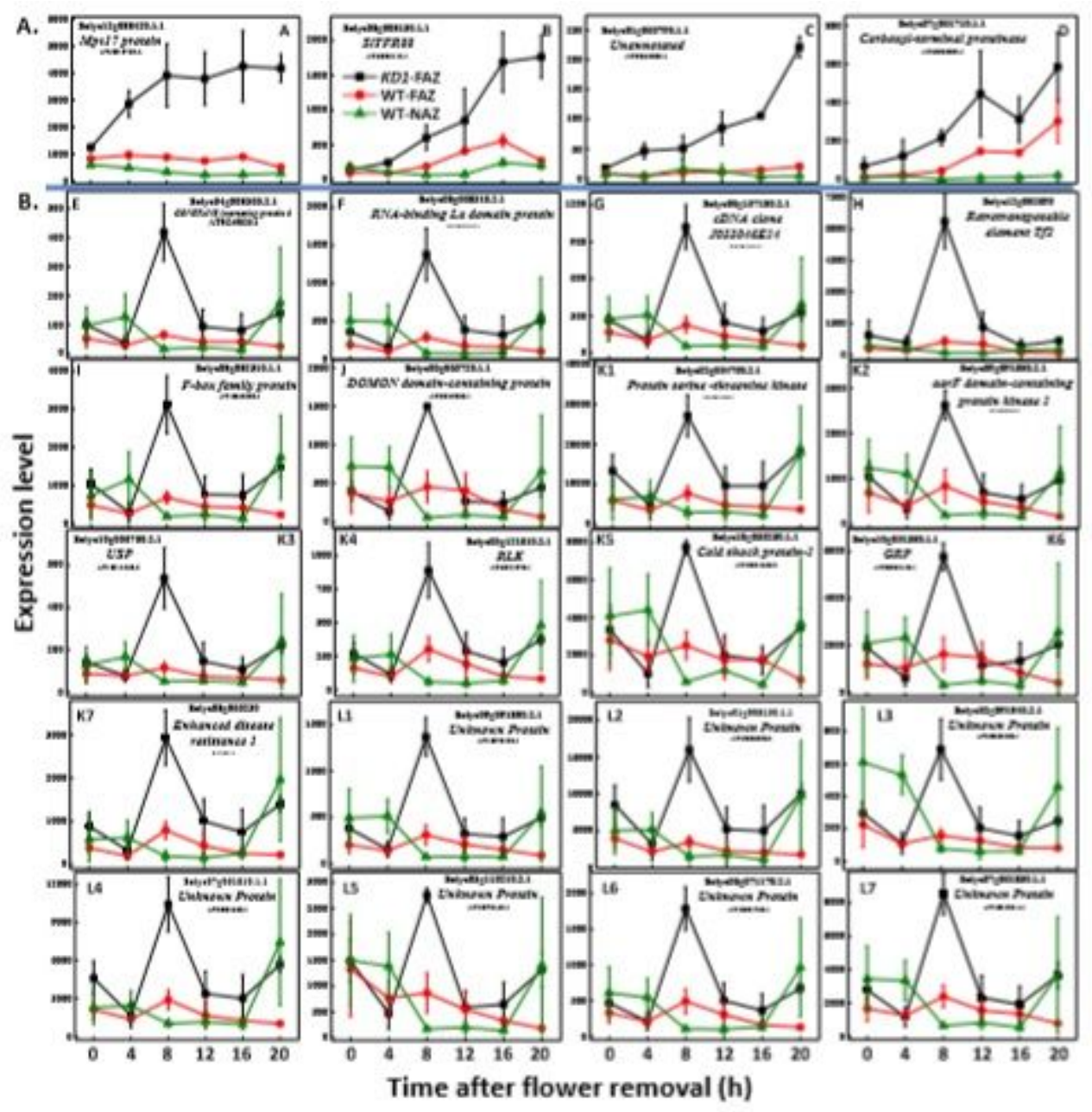

Figure 7

Effect of antisense silencing of KD1 on the kinetics in array-measured expression levels of genes that were specifically continuously (A-D) or transiently (E-L7) upregulated between 0 to $20 \mathrm{~h}$ or at $8 \mathrm{~h}$ after flower removal, respectively, only in the FAZ of TAPG::antisense KD1-silenced plants. Expression levels were measured for the following genes: MpV17 protein (A); SITFR88 (B); Unannotated (C); Carboxylterminal proteinase (D); CONSTANS interacting protein6 (E); RNA-binding La domain protein (F); cDNA clone (G); Retrotransposable element Tf2 (H); F-box family protein (I); DOMON domain-containing protein $(\mathrm{J})$; Protein serine-threonine kinase (K1), aarF domain-containing protein kinase1(K2), Universal Stress Protein (USP) (K3), Receptor-Like Kinase (RLK) (K4), Cold Shock protein-1 (K5), Glycine-rich RNA-binding Protein (GRP) (K6), and Enhanced Disease Resistance1 (K7); and seven Unknown Proteins genes (L1-L7). All other details are as described in Figure 4. 


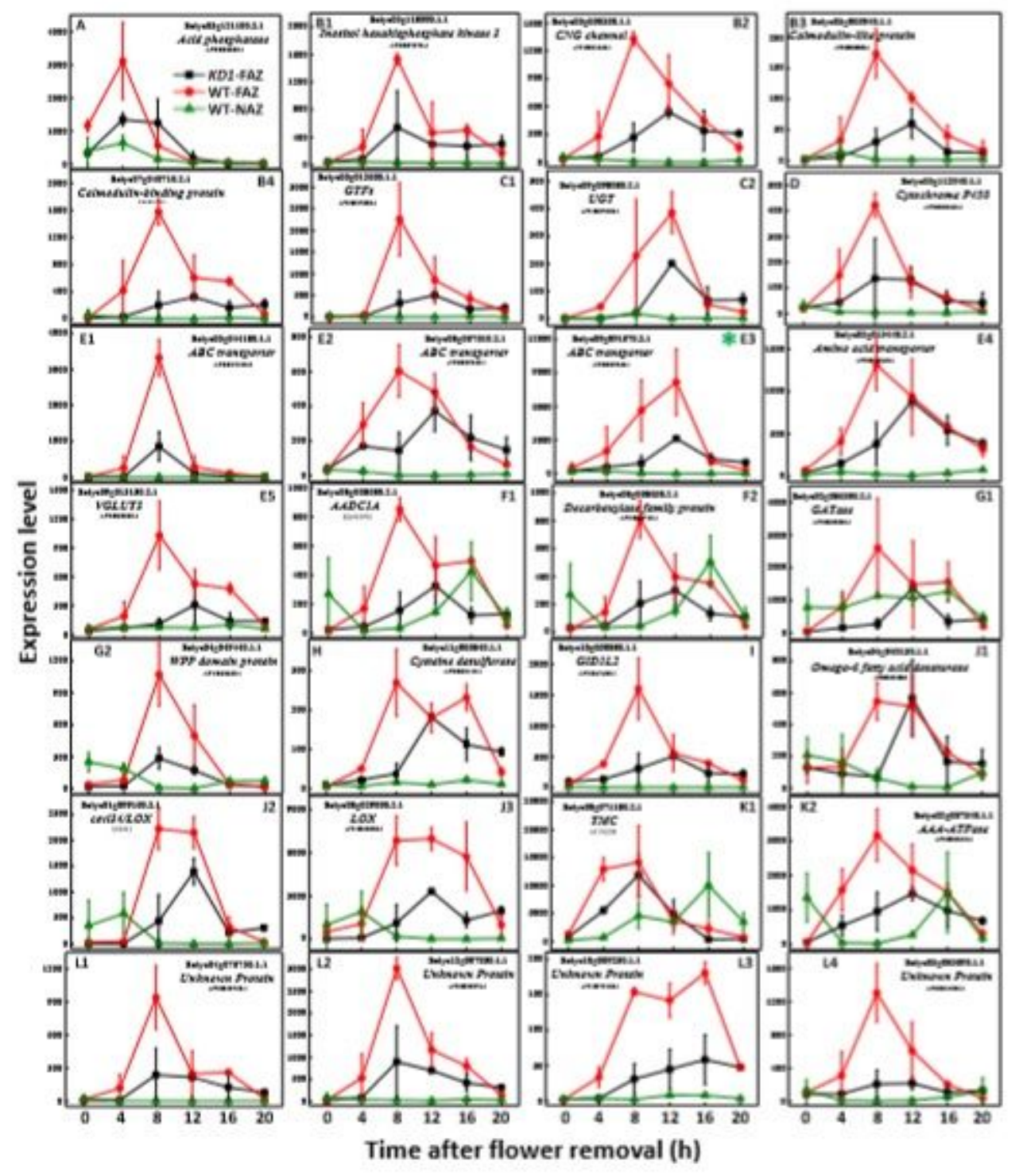

Figure 8

Effect of antisense silencing of KD1 on the kinetics in array-measured expression levels of genes that were specifically and transiently upregulated in the WT FAZ plants, peaking at 4, 8 or $12 \mathrm{~h}$ after flower removal. Expression levels were measured for the following genes: Acid phosphatase (A); Inositol hexakisphosphate kinase3 (B1), Cyclic Nucleotide Gated channel (CNG channels) (B2), Calmodulin-like protein (B3), and Calmodulin-Binding protein (B4); Glycosyltransferases (GFTs) (C1), and UDP-Glucosyl Transferase (UGT) (C2); Cytochromes P450 (D); three ABC transporter family protein genes (E1-E3), Amino acid transporter protein (E4), and Vesicular Glutamate Transporter3 (VGLUT3) (E5); Aromatic Amino acid Decarboxylase1A (AADC1A) (F1), and Decarboxylase family protein (F2); Glutamine Amido Transferases (GATase) (G1), and Tryptophan-Proline-Proline (WPP) domain (G2); Cysteine Desulfurase (H); Gibberellin receptor GID1L2 (I); Omega-6 fatty acid desaturase (J1), cevi34/Lipoxygenase (LOX) (J2), LOX (J3); Multicystatin (TMC) (K1), and AAA-ATPase (K2); and four Unknown Protein genes (L1-L4). All other details are as described in Figure 4. 

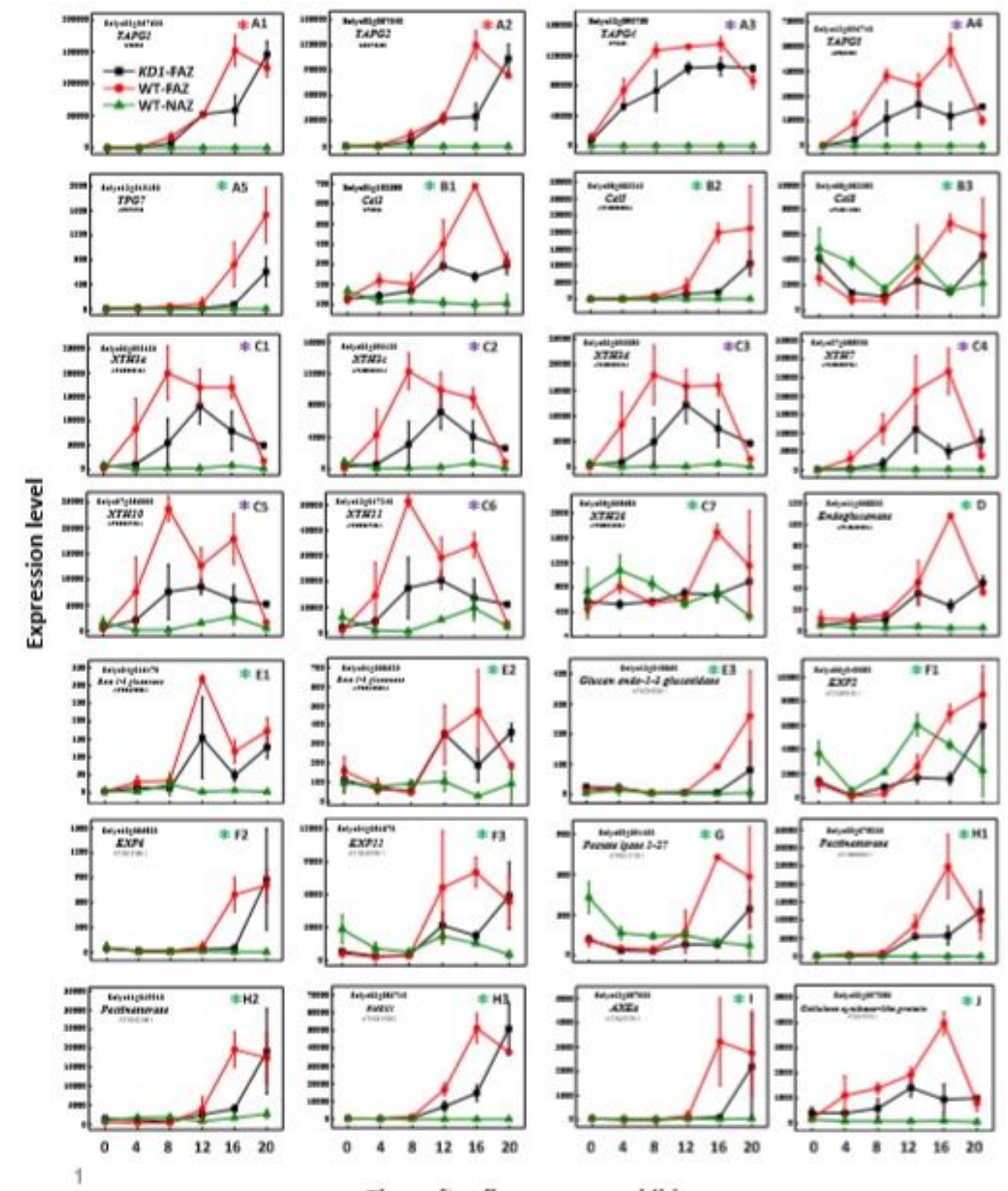

Time after flower removal (h)

\section{Figure 9}

Effect of antisense silencing of KD1 on the kinetics in array-measured expression levels of genes encoding cell wall modifying enzymes that were specifically upregulated in the WT FAZ at specific time points after flower removal: early - $4\left(^{*}\right)$ or $8\left(^{*}\right) \mathrm{h}$ or late 12-20 $\left(^{*}\right) \mathrm{h}$. Expression levels were measured for the following genes: five Tomato Abscission Polygalacturonase (TAPG) genes (A1-A5); three Cellulase (Cel) genes (B1-B3); seven Xyloglucan endo Transglucosylase/ Hydrolase (XTHs) genes (C1-C7);

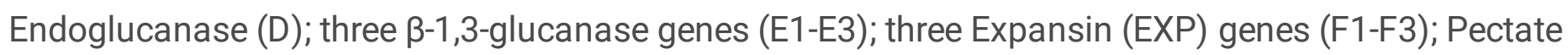
Lyase 1-27 (G); two Pectinesterase genes $(\mathrm{H} 1-\mathrm{H} 2)$, and Pectinesterase/pectinesterase inhibitor U1 (PMEU1) (H3); Acetyl Xylan Esterase a (AXEa) (I); and Cellulose Synthase-Like protein (J). All other details are as described in Figure 4. 

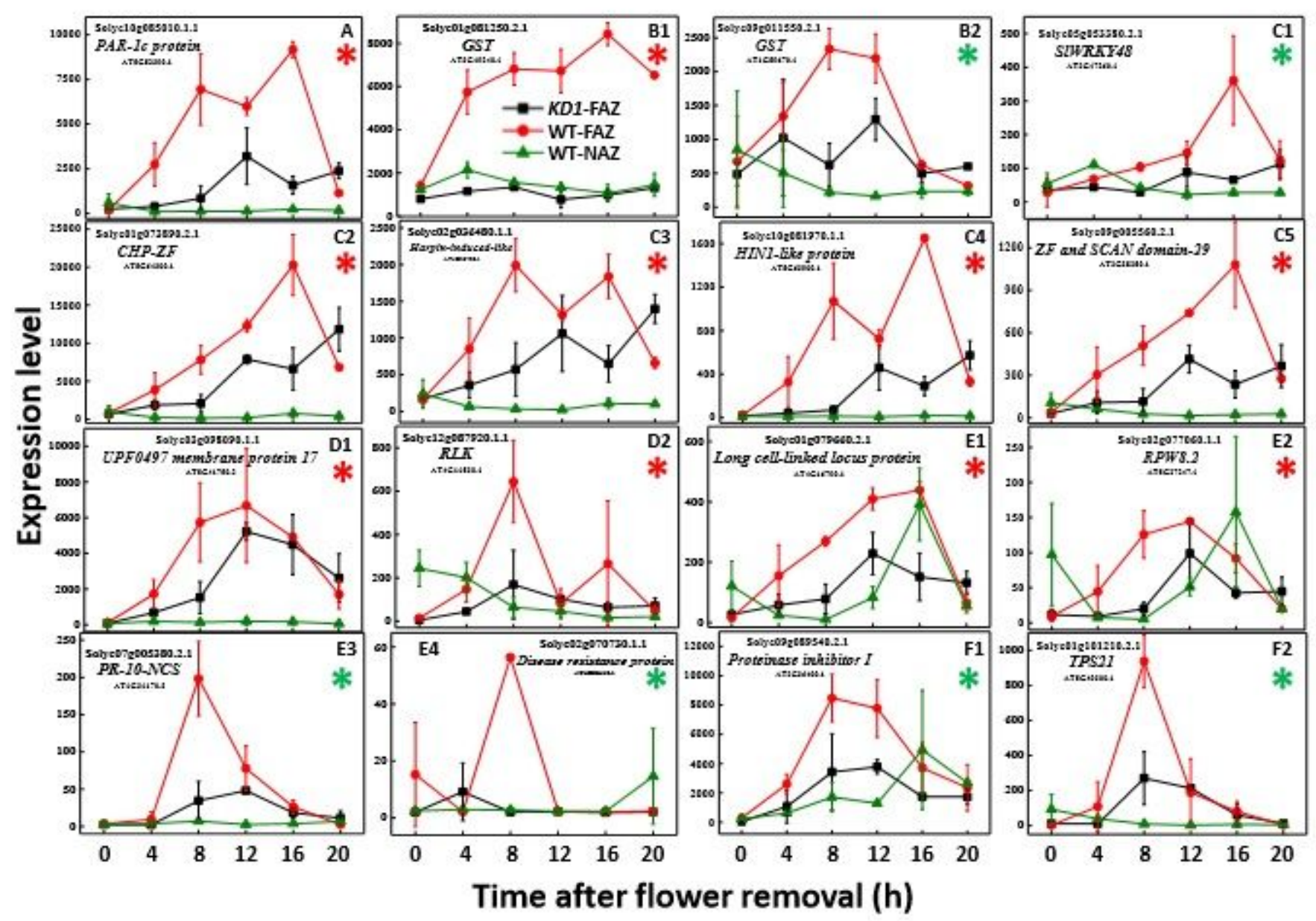

Figure 10

Effect of antisense silencing of KD1 on the kinetics in array-measured expression levels of genes specifically transiently upregulated in the WT FAZ plants at the early stage of abscission, $4\left(^{*}\right)$ or $8\left(^{*}\right) \mathrm{h}$ after flower removal. Expression levels were measured for the following genes: Photo AssimilateResponsive1c protein (PAR-1) (A); two Glutathione S-Transferase protein (GST) genes (B1, B2); Solanum lycopersicum SIWRKY48 (C1), Cysteine/Histidine-rich Zinc Finger protein-like (CHP-ZF) (C2), HarpinInduced-Like (C3), and HIN1-like protein (C4); ZF and SCAN domain-29 (ZSCAN29) (C5); UPF0497 membrane protein17 (D1), and Receptor-Like Kinase (RLK) (D2); Long cell-linked locus protein (E1), Resistance to Powdery Mildew8 (RPW8.2) (E2), PR-10-related Norcoclaurine Synthase-like protein (PR-10NCS) (E3), and Disease Resistance protein (E4); Proteinase Inhibitorl (F1), and a-humulene/(-)-(E)- $\beta$ Caryophyllene Synthase (TPS21) (F2). All other details are as described in Figure 4. 


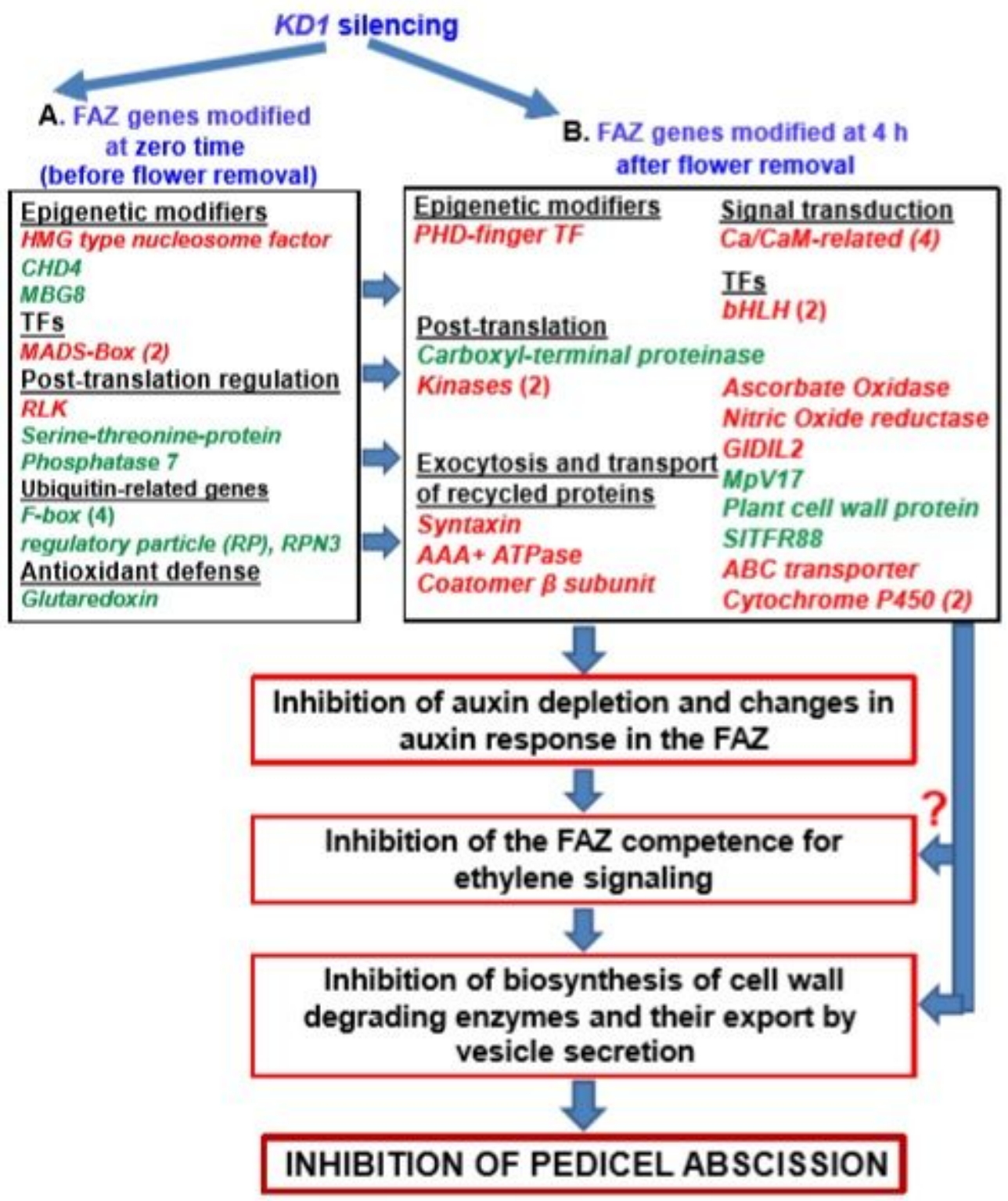

Figure 11

Summary of the genes with altered expression in the FAZ of TAPG4::antisense KD1 plants before (at zero time) and at $4 \mathrm{~h}$ after flower removal in response to KD1 downregulation and abscission induction by flower removal. The altered gene expression led to a decrease of the postulated events resulting in the inhibition of pedicel abscission. Inhibition of auxin depletion and changes in the auxin response in the FAZ at the early abscission stages were demonstrated by Ma et al. [6]. Genes that were specifically upregulated or downregulated in the FAZ of KD1-silenced plants compared to the WT are marked in Green or Red, respectively. The numbers listed besides the gene names indicate the number of genes in the gene family that were affected by KD1 silencing.

\section{Supplementary Files}

This is a list of supplementary files associated with this preprint. Click to download. 
- Additionalfile4TableS4.xlsx

- Additionalfile8Tables7.docx

- Additionalfile3TableS3.xlsx

- Additionalfile2TableS2.xIsx

- Additionalfile7FigureS1.pptx

- Additionalfile1TableS1.xIsx

- Additionalfile5TableS5.xIsx

- Additionalfile6TableS6.xlsx 